\title{
Noise Spectra and Directivity For a Scale-Model Landing Gear
}

\author{
William M. Humphreys, Jr. ${ }^{*}$, and Thomas F. Brooks ${ }^{\dagger}$ \\ NASA Langley Research Center, Hampton, Virginia 23681
}

\begin{abstract}
An extensive experimental study has been conducted to acquire detailed noise spectra and directivity data for a high-fidelity, 6.3\%-scale, Boeing 777 main landing gear. The measurements were conducted in the NASA Langley Quiet Flow Facility using a 41-microphone directional array system positioned at a range of polar and azimuthal observer angles with respect to the model. DAMAS (Deconvolution Approach for the Mapping of Acoustic Sources) array processing as well as straightforward individual microphone processing were employed to compile unique flyover and sideline directivity databases for a range of freestream Mach numbers $(0.11$ - 0.17) covering typical approach conditions. Comprehensive corrections were applied to the test data to account for shear layer ray path and amplitude variations. This allowed proper beamforming at different measurement orientations, as well as directivity presentation in free-field emission coordinates. Four different configurations of the landing gear were tested: a baseline configuration with and without an attached side door, and a noise reduction concept "toboggan" truck fairing with and without side door. DAMAS noise source distributions were determined. Spectral analyses demonstrated that individual microphones could establish model spectra. This finding permitted the determination of unique, spatiallydetailed directivity contours of spectral band levels over a hemispherical surface. Spectral scaling for the baseline model confirmed that the acoustic intensity scaled with the expected sixth-power of the Mach number. Finally, comparison of spectra and directivity between the baseline gear and the gear with an attached toboggan indicated that the toboggan fairing may be of some value in reducing gear noise over particular frequency ranges.
\end{abstract}

\section{Nomenclature}

$\begin{array}{lll}A_{m} & = & \text { shear layer amplitude correction for } \mathrm{m}^{\text {th }} \text { microphone, } \mathrm{dB} \\ \hat{e} & = & \text { column steering vector, see Eq. (4) } \\ f & = & \text { frequency, Hz } \\ \hat{G} & = & \text { cross spectral matrix } \\ \hat{G}_{a v} & = & \text { spectral-averaged cross spectral matrix } \\ \hat{G}_{\text {background }} & = & \text { cross spectral matrix of the background } \\ G_{m m} & = & \text { element of cross spectral matrix for microphone combination } \mathrm{mm}^{\prime} \\ \hat{k} & = & \text { local wavenumber, inches } \\ \hat{k}^{-1} \\ M & = & \text { number of data blocks } \\ M & = & \text { freestream Mach number }\end{array}$

\footnotetext{
${ }^{*}$ Senior Research Scientist, Aeroacoustics Branch, Mail Stop 461, Senior Member AIAA

${ }^{\dagger}$ Senior Research Scientist, Aeroacoustics Branch, Mail Stop 461, Fellow AIAA
} 


$\begin{array}{lll}m_{o} & = & \text { total number of array microphones } \\ P(\hat{e}) & = & \text { array output power for steering vector } \hat{e} \\ p_{m}(t) & = & \text { pressure time series for } \mathrm{m}^{\text {th }} \text { microphone } \\ P_{m}(f, T) & = & \text { transformed (frequency domain) pressure series for } \mathrm{m}^{\text {th }} \text { microphone } \\ r_{m} & = & \text { distance from scanning location to } \mathrm{m}^{\text {th }} \text { microphone, inches } \\ r_{c} & = & \text { distance from scanning location to center of array, inches } \\ R_{e} & = & \text { emission distance, inches } \\ \mathrm{T} & = & \text { size of data block, sec } \\ \hat{W} & = & \text { row matrix containing array microphone weights } \\ w_{s} & = & \text { Hamming window weighting constant } \\ w_{m} & = & \text { Frequency-dependent array microphone weight } \\ \hat{x}_{m} & = & \text { distance vector, inches } \\ x, y, z & = & \text { landing gear coordinate system, origin at reference center of gear (Fig. 4) } \\ \theta_{e} & = & \text { polar emission angle, deg } \\ \phi_{e} & = & \text { azimuthal emission angle, deg } \\ \omega \Delta t_{m} & = & \text { shear layer phase correction, see Eq. (4) }\end{array}$

\section{Introduction}

$\mathrm{O}$ VER the past decade significant progress has been shown in the understanding and modeling of airframe noise generation mechanisms and in the development and testing of practical abatement technologies. Early emphasis was placed on understanding and modeling noise sources generated by high-lift airframe components; i.e., leading-edge slats and trailing-edge flaps, with many papers on the subject having been published in the literature by various researchers including the authors. ${ }^{1,2}$ More recently, emphasis has been given to understanding and modeling the more challenging noise sources generated by the aircraft undercarriage; i.e., the landing gear and wheel well noise. Reduction of landing gear noise has proven to be a remarkably difficult problem due primarily to the complex geometries involved as well as to numerous aerodynamic interactions occurring between gear subcomponents. Early studies of gear noise date to the 1970's with the work of Heller and Dobrzynski ${ }^{3}$ who studied moderately complex two- and four-wheel geometries, yielding separate model scale and flight scale data that could be compared for the first time. In the same time period initial Strouhal-based empirical models of landing gear noise were developed by Fink. ${ }^{4,5}$ Interest in such noise sources waned in the 1980's and early 1990's with researchers concentrating on reducing propulsion and high-lift airframe component noise. However, a resurgence of interest in landing gear and wheel well noise occurred starting in the late 1990's with the experimental work of Dobrzynski et al..$^{6,7}$, Michel et al. ${ }^{8}$, Jaeger, et al. ${ }^{9}$, and Horne et al. ${ }^{10}$, and the modeling work of Smith et al. ${ }^{11}$, Guo ${ }^{12-14}$, Hedges et al. ${ }^{15}$, and Lockard et al. ${ }^{16}$, among others. Most recently, full-scale aeroacoustic flight testing of Boeing 777 and Airbus A319 aircraft to determine airframe and landing gear noise characteristics has been performed. ${ }^{17,18}$ The increased interest in aircraft undercarriage noise has been facilitated largely by the impressive reductions that have been achieved in propulsion noise, allowing "lesser" noise sources such as the landing gear to be seriously considered as candidates for additional noise abatement.

Validation of a prediction model for landing gear noise is incomplete unless the predicted noise can be compared with detailed experimental data obtained on like geometries. In particular, detailed noise spectra collected over a large range of polar and azimuthal directivity angles is a critical component of such a validation. Various examples of landing gear spectra and associated Mach number farfield intensity scalings have been shown in the literature - examples can be seen in Refs. 9 and 10. However, it has proven difficult to collect extensive directivity data for either model- or flight-scale gear configurations, and thus much less of this type of data has been shown with a few exceptions. For example, Heller and Dobrzynski ${ }^{3}$ included limited directivity data acquired at a few sideline measurement points for two- and four-wheel geometries. More recently Michel and Qiao ${ }^{8}$ compared the directivity of landing gear noise measured on various aircraft in flight using a two-dimensional ground based array of microphones. The dataset presented by Michel and Qiao was more complete in that numerous aircraft types and emission angles were measured. Jaeger et al. ${ }^{9}$ measured the directivity of an isolated high-fidelity, $26 \%$-scale Boeing 777 main landing gear at three different emission angles in a hard-walled wind tunnel, followed by measurements at four different emission angles of the same gear attached to a semispan model in an acoustically- 
treated wind tunnel ${ }^{10}$. Detailed testing of the same model, both in baseline and noise treated configurations, was conducted in a hard-walled wind tunnel in 2004. ${ }^{19,20}$ However, these tests did not include extensive directivity measurements. The most complete full-scale directivity measurements reported to date have been those of Pollenske et al. ${ }^{18}$

The goal of the present study was to augment the existing data shown in the literature via the generation of a unique and extensive noise spectra and directivity database using both individual microphone and DAMAS-derived measurements acquired for a high-fidelity, 6.3\%-scale Boeing 777 main landing gear. The database is designed to facilitate validation of new undercarriage noise models, and is currently being used to validate models in the NASA Aircraft Noise Prediction Program (ANOPP). ${ }^{21}$ All aeroacoustic measurements on the scale model gear were obtained in an open-jet anechoic facility using a traversing array of microphones positioned at an ensemble of polar and azimuthal observer angles with respect to the model. The study concentrated on extraction of hemispherical directivity data for the landing gear for typical approach conditions. In addition, Mach number farfield intensity scaling law verifications were conducted. Finally, a limited noise treatment investigation was attempted, using a fairing attached to the bottom of the gear truck. ${ }^{22}$ This paper presents an overview of the study and shows representative data obtained from the measurements.

\section{Test Program}

\section{A. Test Apparatus}

The model used for this study was a $6.3 \%$-scale high-fidelity Boeing 777 main gear assembly that was previously tested as part of an overall semi-span model. ${ }^{23}$ The high complexity gear is comprised of a six-wheel bogie and a generally faithful representation of full-scale strut, oleo, braking, and hydraulic hardware. The four configurations of the model tested in this study are shown in Fig. 1. The overall model height is approximately 12 inches. The side-to-side width of the model is five inches. The length and diameter of the oleo are approximately 8.5 inches and one inch, respectively. The strut component widths are approximately 0.5 inches. The truck length is eight inches, and the wheel width and diameter are 1.25 and 3.25 inches, respectively. The model is fabricated with load-bearing metal components and stereo lithography detailed components. Standard electrical wiring and pressure tubing (ranging from 3/64 to 5/64 inches) are used to roughly simulate the hydraulic lines and cables. These are generally a little larger than scale. The attached door for the baseline configuration in Fig. 1 is about four by five inches with a thickness of $1 / 8$ inch. A noise-reduction concept "toboggan" fairing was tested with and without the door as shown. This 3/64 inch-thick fairing is mounted on the truck underside to cover brake hardware and hydraulic lines. The front of the fairing is curved and partially wraps around the front axle.

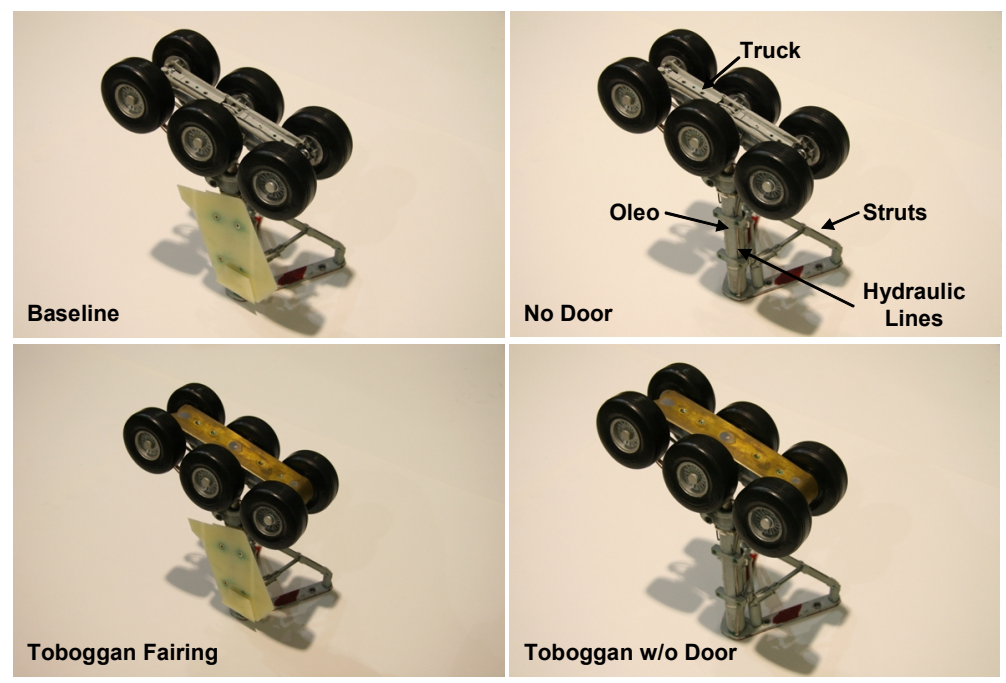

Figure 1. Boeing 777 main landing gear tested configurations. 
Measurements were conducted in the NASA Langley Quiet Flow Facility ${ }^{24}$ (QFF), an open-jet facility specifically designed for aeroacoustic testing. Using a two by three-foot rectangular nozzle oriented vertically in a $14,400 \mathrm{ft}^{3}$ anechoic chamber, a maximum freestream Mach number of 0.17 can be attained. The shorter sides of the nozzle are bounded by fixed sideplates to which test articles can be attached. Figure 2 shows the model mounted to a treated portion of the sideplate. The intent of the treatment is to create an acoustically compliant surface near the model while maintaining a flat boundary for the flow. The surface is achieved by stretching thin Kevlar ${ }^{\circledR}$ fabric over an open-backed ribbed frame, thus reducing acoustic surface reflections. The mounting shown in Fig. 2 represents the set-up used for "sideline" viewing of the landing gear model by the boom-mounted microphone array. For "flyover" viewing of the landing gear model, a removable 23.5 inch wide sideplate was specially constructed and

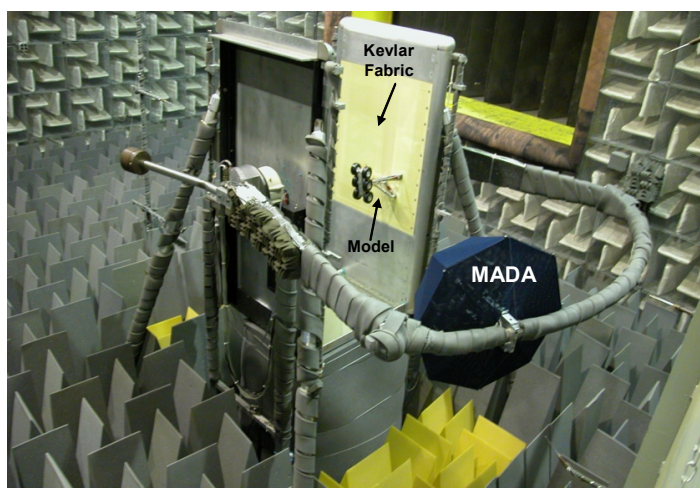

Figure 2. Model mounted in QFF for sideline viewing.

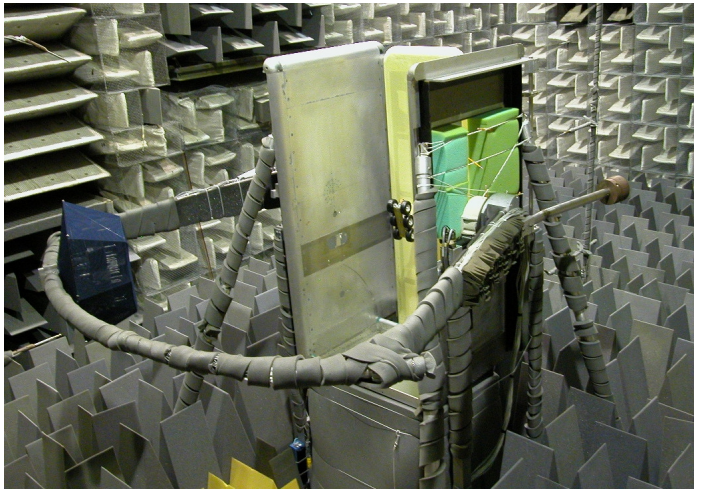

Figure 3. Model mounted in QFF for flyover viewing.

mated along a three-foot side edge of the nozzle. This is shown in Fig. 3, illustrating the method by which the array could view the landing gear "underneath" flyover positions. The flyover sideplate is correspondingly covered with $\operatorname{Kevlar}^{\circledR}$ fabric over an open-backed ribbed frame.

For either orientation of the landing gear model, the coordinate system shown in Fig. 4 was employed during analysis of the directivity data. The reference center of the landing gear is defined to be the center of the truck assembly. The coordinate system, defining the $\mathrm{x}$ axis as being aligned with the direction of flight and the $\mathrm{z}$ axis directed under the flight path, corresponds to the coordinate system used in noise prediction codes currently under evaluation in a companion paper by Burley, et al. ${ }^{21}$ Using this coordinate system, observer locations can be specified by an observer distance $R_{e}$ and two angles with $\theta_{e}$ denoting the polar flyover angle and $\phi_{e}$ denoting the azimuthal sideline angle. The $e$ subscript indicates that these are emission coordinates determined from tunnel, array, and landing gear mounting geometries, along with corresponding shear-layer acoustic refraction corrections. Derivation details of the model coordinate system and its relationship to the tunnel coordinate system are given in Appendix A.

Acoustic spectra and directivity data for the model were obtained with the Langley Medium Aperture Directional Array (MADA). The MADA consists of 41 B\&K Model 4138, 1/8-inch microphones with $1 / 4$-inch preamplifiers mounted on an acoustically treated frame and covered with a hood of thin woven nylon fabric to reduce microphone self-noise due to recirculating air currents

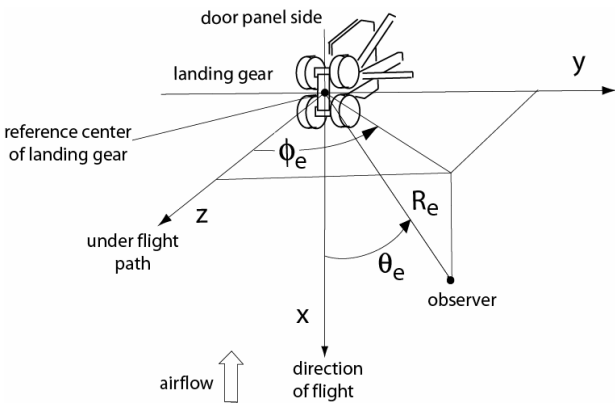

Figure 4. Landing gear coordinate system. within the QFF. The hooded array as seen in Figs. 2 and 3 is boommounted and faces the model region. Figure 5 is a photo of the MADA with the front hood removed to show the overall mounting. Figure 6 shows the arrangement of the array microphones as viewed from the source region when 


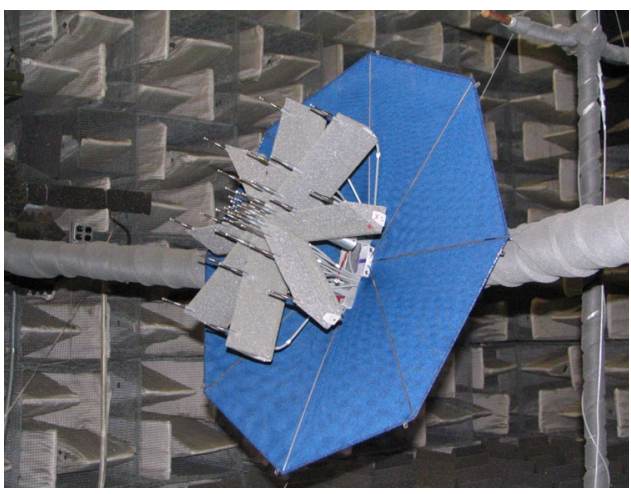

Figure 5. MADA with front protective hood removed.

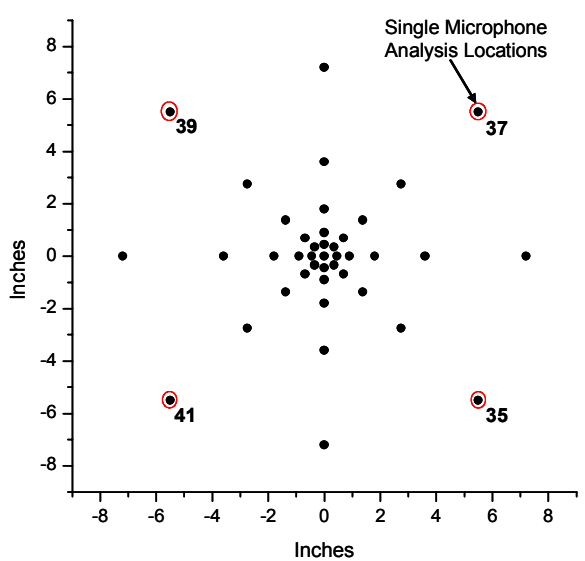

Figure 6. MADA microphone arrangement.

the array is on the negative $\phi_{e}$ side of the model. The MADA includes five circles of eight microphones with one microphone mounted in the center (also serving as the phase center of the array). The inner four circles and the single central microphone correspond to the SADA (Small Aperture Directional Array) geometric arrangement. ${ }^{25}$ The circles are irregular in the sense that the horizontal and vertical arm microphone spacings are slightly larger than the ones in the diagonal arms. The pivotal boom is attached to the QFF fixed sideplates and allows positioning of the array at a large range of polar and azimuthal angles. For the single microphone analyses shown in this report, the four microphones shown circled in Fig. 6 were used independently. At a nominal source region distance of five feet, these microphones (numbered 35, 37, 39, and 41) span a polar and azimuthal angular range of approximately 10 degrees in solid angle from the center of the boom rotation.

\section{Data Acquisition and Post-Processing}

Data were acquired from the array microphones using individual transient data recorders controlled by a central UNIX workstation. All acquisition channels were simultaneously sampled at a rate of $142.857 \mathrm{kHz}$ (corresponding to a $7 \mu \mathrm{sec}$ sampling period) using 14 bits of dynamic range. Two million 2-byte samples were collected for each acquisition, with the signals conditioned by bandpass filtering over a pass band of $300 \mathrm{~Hz}$ to $50 \mathrm{kHz}$. The upper limit represents $70 \%$ of the Nyquist frequency for the chosen sampling rate.

Post processing of acquired array data included single microphone auto-spectrum analysis, conventional beamforming, and DAMAS deconvolution. In all cases a cross spectral matrix (CSM) was first formed from the time series data, taking the form of

$$
\hat{G}=\left[\begin{array}{cccc}
G_{11} & G_{12} & \cdots & G_{1 m_{o}} \\
\vdots & G_{22} & & \vdots \\
\vdots & & \ddots & \vdots \\
G_{m_{o} 1} & & & G_{m_{o} m_{o}}
\end{array}\right] .
$$

The individual, block-averaged complex spectral elements are computed via

$$
G_{m m^{\prime}}(f)=\frac{2}{K w_{s} T} \sum_{k=1}^{K}\left[P_{m k}^{*}(f, T) P_{m^{\prime} k}(f, T)\right]
$$

where the frequency-domain pairs $P_{m}(f, T)$ and $P_{m^{\prime}}(f, T)$ are formed via Fast Fourier Transforms (FFT) of the corresponding microphone pressure time records $p_{m}(t)$ and $p_{m^{\prime}}(t)$, respectively. The time data are segmented 
into a series of $K=250$ non-overlapping blocks of 8192 samples each. $w_{s}$ represents a weighting constant for the Hamming window which was applied to each time record block.

For the diagnostic portion of this study, conventional beamforming ${ }^{25}$ and DAMAS ${ }^{26-28}$ were used. The diagonal removal form of conventional beamforming was used to create global beamform contour levels of noise sources generated by the landing gear. The conventional beamformer couples steering vectors with the CSM to electronically scan the array to predefined locations on a grid, measuring a "mean-squared-pressure" $P(\hat{e})$ at each grid point using

$$
P(\hat{e})=\frac{\hat{e}^{T} \hat{W}\left(\hat{G}-\hat{G}_{\text {background }}\right)_{\text {diag }=0} \hat{W}^{T} \hat{e}}{\left(\sum_{m=1}^{m_{o}} w_{m}\right)^{2}-\left(\sum_{m=1}^{m_{o}} w_{m}\right)}
$$

where $w_{m}$ is a frequency-dependent weighting function ${ }^{29}$ designed to yield an invariant array beamwidth (approximately equal to one foot at an array focal length of five feet) over a broad frequency range spanning 5 to $40 \mathrm{kHz}$ for the MADA. $\hat{W}$ is a row matrix containing the $w_{m}$ terms. The term $\left(\hat{G}-\hat{G}_{\text {background }}\right)_{\text {diag }=0}$ is a resultant CSM formed by subtracting the corresponding CSM of the reference model-removed case, and also zeroing the diagonal $G_{m m}$ terms of Eq. (1). The CSM procedure of Eq. (3) was used to reduce overall beamforming background noise and microphone self-noise. The steering vector $\hat{e}$ is a column matrix containing one entry $e_{m}$ for each microphone in the array. Here

$$
e_{m}=A_{m} \frac{r_{m}}{r_{c}} \exp \left\{j\left[\left(\hat{k} \cdot \hat{x}_{m}\right)+\omega \Delta t_{m, \text { shear }}\right]\right\}
$$

where $\hat{k}$ is the local wavenumber vector and $\hat{x}_{m}$ is the distance from the steering location to microphone $m$. The ratio $\left(r_{m} / r_{c}\right)$ normalizes the amplitude, based on spherical spreading, to that of the reference center microphone at a distance of $r_{c}$. The phase correction $\omega \Delta t_{m}$ for microphone $m$ accounts for the refraction of sound transmission through the shear layer. Figure 7 illustrates the landing gear noise source region with respect to the out-of-flow array. The "actual ray path" shown is accounted for in the phase calculation of Eq. (4) and the amplitude effect of the shear layer refraction is accounted for in the $A_{m}$ amplitude correction. The correction calculations, detailed in Humphreys, et al. ${ }^{25}$, are based on Amiet's method. ${ }^{30}$ For this paper, the emission polar angle $\theta_{e}$ shown in Fig. 7 corresponds to that of the emission spherical coordinate system for the landing gear directivity definition in Fig. 4. Details of coordinate values for the test matrix for the present paper are given in Appendix A.

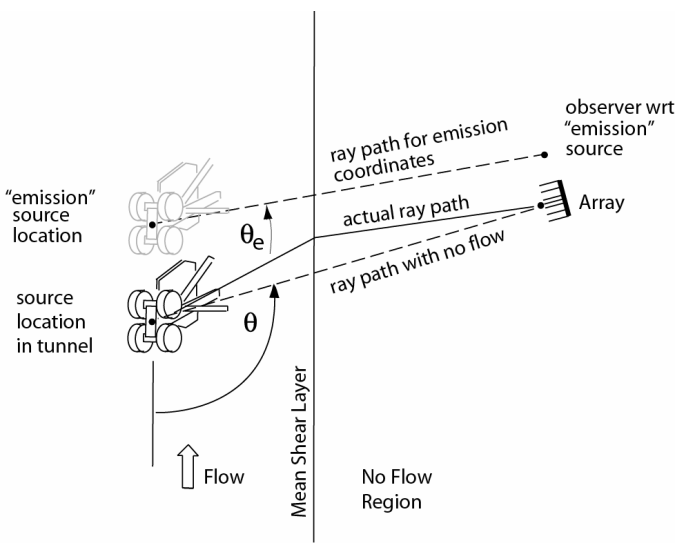

For most of the spectral presentations of this report, single microphone autospectra are used. In those cases, specific microphones are defined by their emission polar and azimuthal angles and the spectra corrected for shear layer refraction. This is accomplished by using the autospectra component $G_{m m}$ in Eq. (1), the steering vector component $e_{m}$ of Eq. (4), and a limiting form of Eq. (3). That is

$$
P_{m}(\hat{e})=e_{m}^{*} G_{m} e_{m}
$$


or with background subtraction

$$
P_{m}(\hat{e})=e_{m}^{*}\left(G_{m}-G_{m, \text { background }}\right) e_{m}
$$

The DAMAS deconvolution algorithm was used along with the beamformer to obtain apparent source distributions around the model. DAMAS is a method for removing the effects of the array point spread function from the beamformer output, resulting in presentations which are explicit and straightforward. ${ }^{26-28}$ As described in Ref. 26, the basic premise behind the DAMAS algorithm is the generation of a series of modeled cross spectral matrices for each location in the array scanning grid. These modeled CSM's are used to generate a series of modeled array outputs which are then equated with processed array outputs (computed using Eq. (3)) to obtain a set of linear equations. The linear equations are solved using an iterative relaxation solver to form the final deconvolved array output. After the deconvolved array output is generated, the integrated noise radiated from regions of interest can be determined via a simple summing of mean-squared pressures over each region. For this paper, in the manner of Refs. 26-28, beamforming and DAMAS results were first separately obtained in narrowband and then summed to obtain the one-third octave results presented. All reported frequencies are in the as-measured model scale and the levels are referenced to a five-foot distance between the model and microphones.

\section{B. Test Matrix}

The test matrix for the study is summarized in Table 1. The four different configurations of the landing gear model that were tested are shown in Fig. 1. The configurations include: a baseline geometry where the gear is fully configured with all hardware including an oleo side door, a geometry where the side door is removed, and two geometries (with and without the side door present) where the toboggan fairing is attached to the underside of the gear truck. The fairing completely covers the brake hardware and hydraulic lines with respect to "flyover" observer positions. A Mach number range of 0.11 to 0.17 was tested to cover typical approach velocities for the 777 aircraft. The Mach number range yields a Reynolds number range based on wheel diameter of $2.1 \times 10^{5}$ to $3.3 \times 10^{5}$. Finally, a range of polar and azimuthal angles were chosen for acquisition such that a sizeable portion of the hemispherical directivity of the gear could be obtained.

Table 1. Test Matrix for Experimental Study.

\begin{tabular}{|l|l|}
\hline Model Configurations Tested & $\begin{array}{l}\text { Baseline (with and without side door), } \\
\text { Toboggan (with and without side door) }\end{array}$ \\
\hline Model Mounting / Views & Flyover, Sideline \\
\hline Mach Numbers & $0.11,0.13,0.15,0.17$ \\
\hline Reynold's Number Range (based on wheel diameter) & Approximately $2.1 \times 10^{5}$ to $3.3 \times 10^{5}$ \\
\hline Polar Angular Range (emission angles) & Approximately 55 to 135 degrees \\
\hline Azimuthal Angular Range (emission angles) & Approximately -106 to 94 degrees \\
\hline
\end{tabular}

\section{Results and Discussion}

The primary purpose of this paper is to establish model directivity and spectra. With the moveable MADA, this can be accomplished by integration of beamform contours, integration-by-simple-summing over DAMAS source distributions, or by employing the autospectra of individual microphones. Note that beamform integrations can be inaccurate. In contrast, DAMAS typically produces accurate and spatially discriminating results. Single microphone results can be accurate if the results can be shown to be dominated by direct noise radiation from the model region. Although DAMAS is processed for the whole test matrix and can be used for directivity definition, the use of individual microphone autospectra permits a more detailed spatial distribution. Also, an advantage using individual microphones is that there is less potential interpretation difficulty at important lower frequencies for the landing gear - frequencies outside of the MADA / DAMAS design range.

In the following sections, spatial distributions of noise sources about the landing gear model configurations are viewed from several observer locations using DAMAS for a particular one-third octave band. Also, DAMAS integrated spectra are compared with those of microphone autospectra, in order to establish the validity of the

Page 7 of 22

American Institute of Aeronautics and Astronautics 
subsequent use of single-microphone spectra to determine scaling characteristics and detailed global landing gear noise directivity.

\section{A. DAMAS Noise Source Distributions}

Figure 8 shows an array response contour plot obtained for a 10-kHz one-third octave band at a Mach number of 0.17 , using conventional beamforming with spectral background subtraction and CSM diagonal removal as defined in Eq. (3). For this specific measurement, Fig. 2 shows the orientation of the array with respect to the mounted baseline model. Corresponding emission polar and azimuthal angles $\theta_{e}$ and $\phi_{e}$ are $91.8^{\circ}$ and 52.9 ${ }^{\circ}$, respectively. Spanwise and streamwise coordinates shown are with respect to a planar beamforming grid with one-inch spacing, a height of 48 inches, and a width of 50 inches. The center of the grid passes through the reference center of the landing gear, and the grid is oriented to be normal to a line connecting the center of the array with the landing gear reference center. The silhouette of the model is shown in perspective as viewed by the center of the array. The dotted lines in the figure define regions of negative "pressure-squared" values produced by the diagonal removal beamforming. Although not shown in the figure, the position of the sideplate to which the model is attached can be inferred from the location of the gear-mounting bracket. The peak sound pressure level (SPL) shown in the figure is $70.6 \mathrm{~dB}$. As is typical with conventional beamformer presentations of this type, the array point spread function is the predominant feature seen in the figure, with the beamwidth of the array at this frequency approximately one foot. At this resolution it is difficult to ascertain much information concerning noise source distributions around the landing gear. The two beamform lobes seen on the left hand side of the figure in the vicinity of the opposite sideplate are apparently array sidelobes.

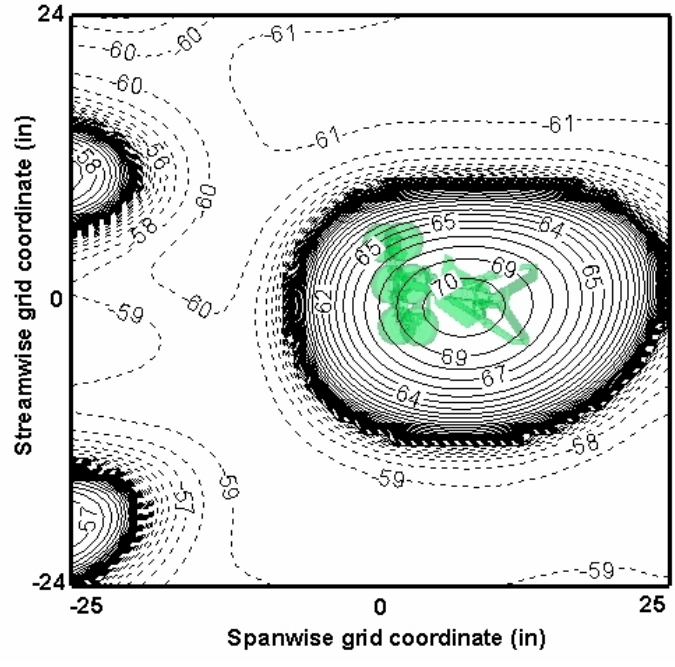

Figure 8. Typical beamform contours using standard MADA processing. $\mathrm{M}=\mathbf{0 . 1 7}, \mathrm{f}_{1 / 3}=10 \mathrm{kHz}, \theta_{\mathrm{e}}=91.8^{0}, \varphi_{\mathrm{e}}=52.9^{\circ}$

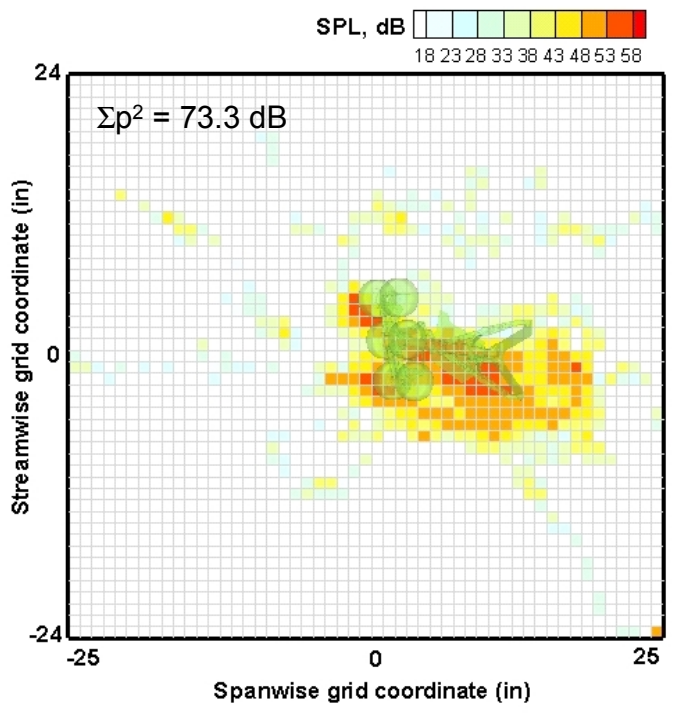

Figure 9. DAMAS presentation corresponding to Figure 8.

Figure 9 shows a DAMAS presentation corresponding to that of the beamform contour in Fig. 8 using the same grid. The number of DAMAS solver iterations employed to obtain the solution shown is 2000 . It appears obvious that removal of the array point spread function greatly improves the presentation and effective resolution of the array. The figure shows identifiable noise features in the vicinity of the landing gear truck and oleo. The maximum SPL shown in the figure is $57.7 \mathrm{~dB}$, and the full window integrated SPL (corresponding to an equivalent single microphone measurement) is $73.3 \mathrm{~dB}$. The lack of any sources in the DAMAS output at the two locations seen on the left hand side of Fig. 8 confirms that they are array sidelobes removed by the deconvolution. It is seen that the majority of the measured sound is generated very close to the model. 
A mosaic of DAMAS noise source distributions is presented in Fig. 10 for all four model configurations of Fig. 1. Again, the Mach number is 0.17 . These results are obtained by combining all one-third octave bands from $6.3 \mathrm{kHz}$ through $31.5 \mathrm{kHz}$ (about $400-2000 \mathrm{~Hz}$ for full-scale). These are thus representative of high-frequency model-scale noise or mid-frequency full-scale landing gear noise. The $10 \mathrm{kHz}$ results of Fig. 9 are summed into the noise distribution of the top right corner of the Fig. 10 mosaic. For each model configuration, a door-side sideline view at $\theta_{e}=92.0^{\circ}$ and $\phi_{e}=-63.9^{\circ}$, a flyover view at $\theta_{e}=93.1^{\circ}$ and $\phi_{e}=-6.0^{\circ}$, and a non-door sideline view at $\theta_{e}=91.8^{\circ}$ and $\phi_{e}=52.9^{\circ}$ are shown. The silhouette used in Fig. 9 has been replaced by a simple gear outline in Fig. 10 to avoid interference with the presentation of results. The total integrated DAMAS levels in the band range are giving in the upper portion of each frame. All of the plots in Fig. 10 are shown with the same $\mathrm{dB}$ color range. (Note that as explained in Ref. 21, these levels would match those of full-scale for observers at the same angle orientations but at a distance away of $5 \mathrm{ft}$. x 1/0.063=79.4 ft.)

The DAMAS results for the baseline configuration appear to reveal two general regions of noise emission from the landing gear - the truck assembly and the oleo / strut brace assembly. Such a finding is consistent with previous aeroacoustic studies performed on similar models. ${ }^{9,10,19,20}$ The oleo / strut noise appears most dominant in the nondoor, sideline view. This noise region is less well defined for the door sideline view perhaps due to the strut orientation and partial obscuration by the door. The oleo and strut noise are less visible in the flyover view, but the truck/wheel noise seems apparent. This noise tends to be concentrated in the vicinity of the mid and rear brake assemblies, a finding consistent with data presented in Ref. 19. Note that the spatially integrated levels are about the same for the flyover and door sideline, whereas the non-door sideline is about $2 \mathrm{~dB}$ higher. The next row of panels shows the results when the oleo-mounted door is removed from the model. For this frequency band, very little change is observed for the non-door sideline and flyover views compared to the door mounted case. However, on the side where the door would normally be mounted, there is a total level increase of over $1 \mathrm{~dB}$ with a small increase in the apparent size of the source region.

The noise distribution resulting from installation of the toboggan truck fairing is shown in the third set of panels in Fig. 10. As the fairing covered the underside of the truck, it was intended to provide shielding for noise generated by the brake assemblies and other small-scale structures attached to the truck (e.g., cable harnesses) for flyover observers. As perhaps to be expected, Fig. 10 shows little change from the no-toboggan case for door and non-door sideline views. For the flyover view the total integrated DAMAS level decreases about $1.5 \mathrm{~dB}$, mostly due to noise reduction in the vicinity of the toboggan fairing. Similar observations can be made when the side door is removed (bottom panels), with the flyover view again showing the same reduction in level. The sideline views show very similar results to the corresponding no-toboggan-fairing baseline cases.

\section{B. Spectral Characteristics and Scaling}

A comparison of narrowband $(\Delta \mathrm{f}=17.44 \mathrm{~Hz})$ spectra is shown in Fig. 11 for the measurement condition of Fig. 9. Eq. (5) was used to compute the "raw" autospectrum of individual microphones in the array (whose locations are indicated in Fig. 6). This equation was also used to obtain the background spectrum, whereas Eq. (6) was used to obtain the microphone with background-subtracted spectrum. The "single microphone" spectra shown in Fig. 9 are actually an average of all spectra for the microphones in the outer ring of the array. This average was taken in order to more properly compare individual microphones to the complete array results represented by the DAMAS spectra. It is seen that model related noise clearly dominates the spectra, except at low frequency. The background subtraction appears to properly correct for the contamination of low-frequency test section noise, as well as that of the high-frequency background spectral "hump". This "hump" is sideplate Kevlar "scrubbing" noise and has been documented by other researchers. ${ }^{31}$ Superimposed on and agreeing with the single microphone spectra is the DAMAS spectrum, which was determined by summing DAMAS maps at the same narrowband resolution. For the DAMAS spectrum, it is noted that data is missing in a range about $1 \mathrm{kHz}$. The DAMAS algorithm had difficulty with this particular frequency range because not only was it below the intended design range for the MADA, there were possibly coherent reflection effects in the test setup. (It is likely that the DAMAS-C algorithm in Ref. 28 could address this, but the use of DAMAS-C was beyond the scope or need of this study.) The key result of Fig. 11 is that the single microphone spectrum with the background properly subtracted represents the noise emitted from the landing gear model. This was found to be true in numerous case comparisons. In some cases, particularly for the flyover test configuration where there was substantial Kevlar ${ }^{\circledR}$ material present, high frequency background noise became too high to properly subtract out. Such data are omitted in subsequent presentations.

Page 9 of 22

American Institute of Aeronautics and Astronautics 


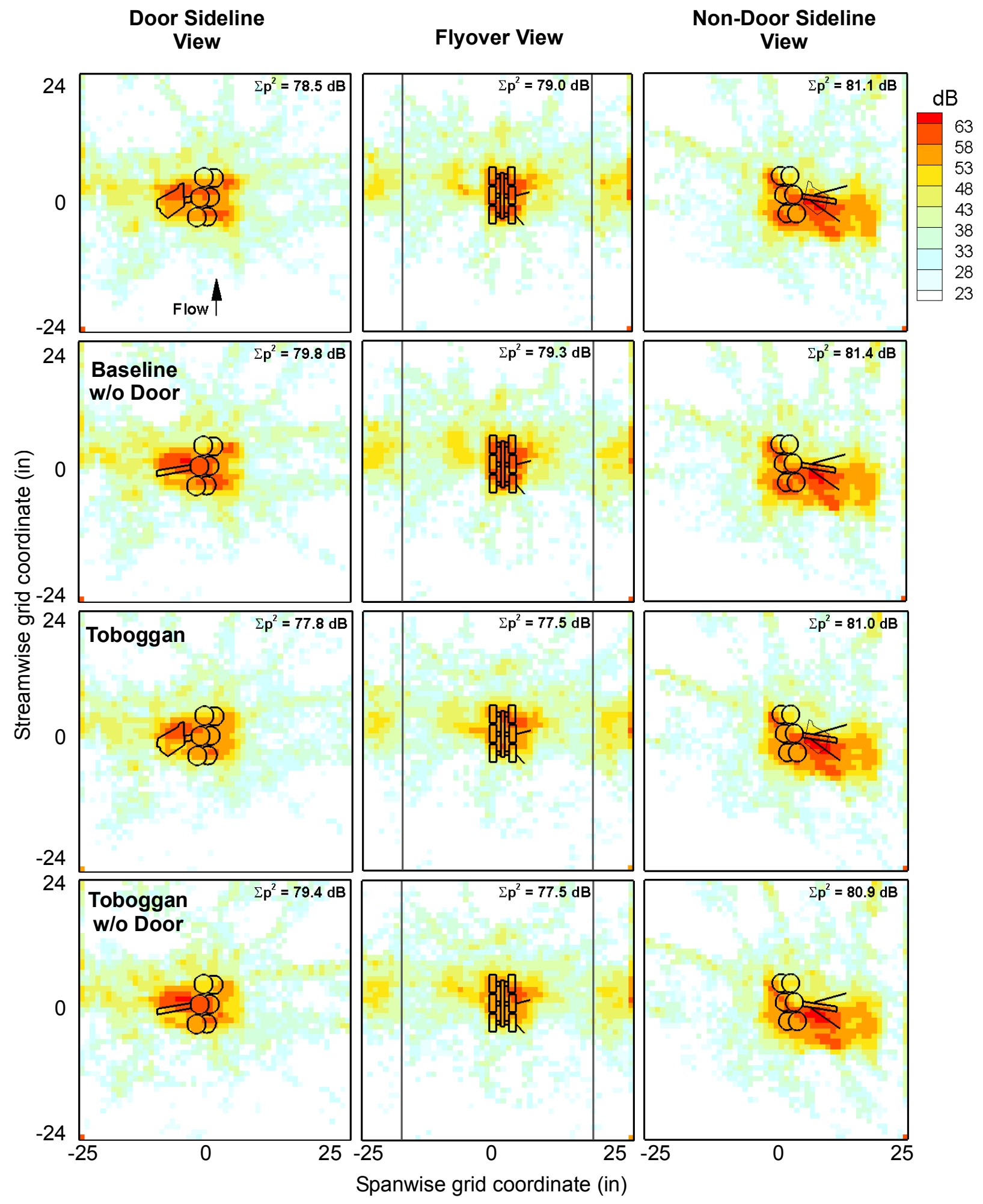

Figure 10. Broadband integrated DAMAS contours for tested landing gear configurations, $M=0.17$. 
The basic landing gear spectral characteristic shown in Fig. 11 is of a broad, narrowband spectrum without strong tonal content. The somewhat bumpy appearance is mostly caused by sideplate reflections. The reflections are actually relatively mild due to the Kevlar presence. For such broadband spectra in aeroacoustics, particularly for airframe noise where the noise is surface dipole in origin and flow similarity conditions with respect to velocity and surface size are expected, one would expect Strouhal spectral scaling to be valid. With this being the case, the use of one-third octave spectral presentations are traditional and often preferred. The distribution of spectral energy in the bands make it suitable for Strouhal spectral scaling because bandwidth is proportional to frequency and is thus proportional to Strouhal number (reference length times frequency divided by velocity). Such scaling also serves to smooth the spectra.

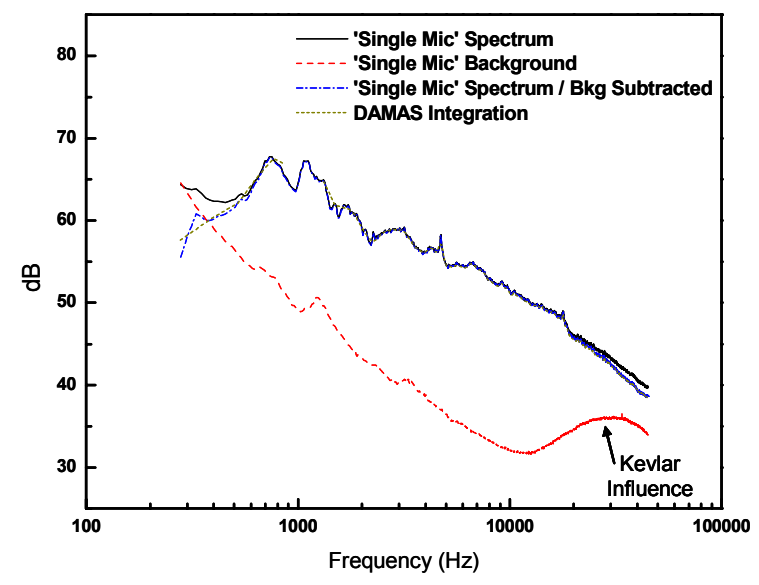

Figure 11. Narrowband single microphone and DAMAS spectra, $M=0.17, \theta_{\mathrm{e}}=91.8^{\circ}, \varphi_{\mathrm{e}}=\mathbf{5 2 . 9}^{\circ}$

One-third octave presentations of spectra for the flyover position for the baseline model for a range of tunnel speeds are shown in Fig. 12. For $\mathrm{M}=0.17$, the emission angles are $\theta_{e}=87.1^{\circ}$ and $\phi_{e}=-1.0^{\circ}$ (microphone 35 was used). These angles are very similar at the other tested speeds. The data is scaled, in a manner consistent with Strouhal scaling, in Fig. 13 using the $\mathrm{M}=0.17$ data as the reference amplitude and frequency. The scaling employs a

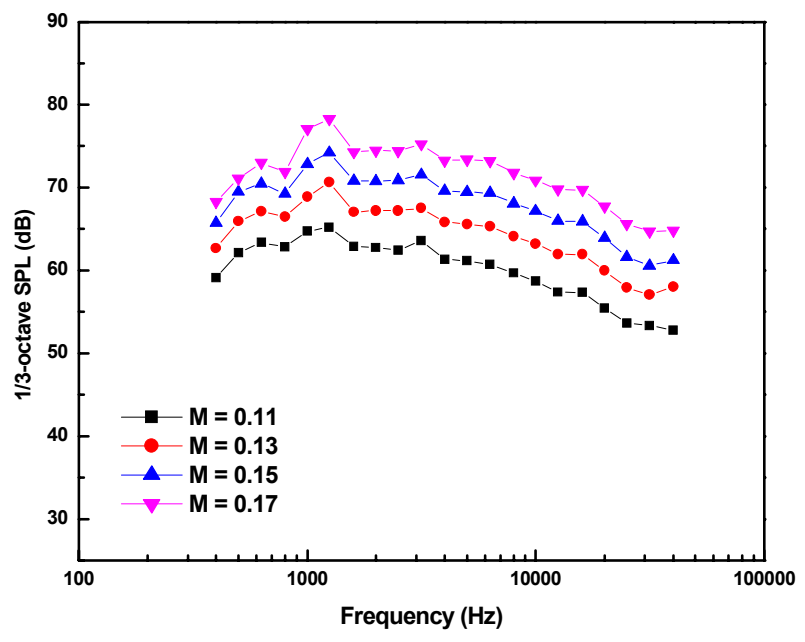

Figure 12. Auto spectra Mach \# dependence. $\theta_{\mathrm{e}}=\mathbf{8 7 . 1}^{\circ}, \varphi_{\mathrm{e}}=-1.0^{\circ}$

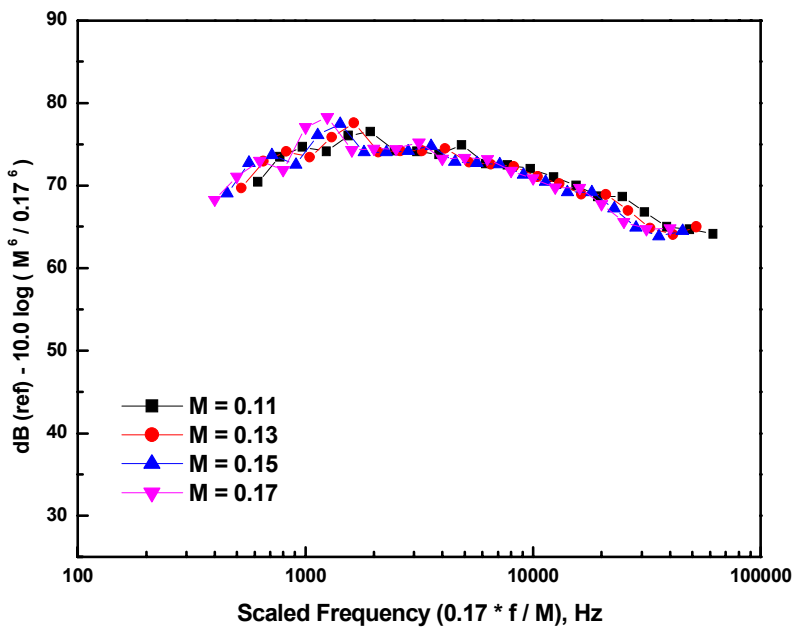

Figure 13. Auto spectra Mach \# scaling. $\theta_{\mathrm{e}}=87.1^{\circ}, \varphi_{\mathrm{e}}=-1.0^{\circ}$ 
sixth-power of Mach number dependence assumption. Similar sixth-power scaling success was found over a range of directivities for all model configurations. It can be seen in Fig. 13 that the best collapse of the data occurs between 2 and $30 \mathrm{kHz}$. From Fig. 13, one would perhaps judge $3 \mathrm{kHz}$ with respect to the $\mathrm{M}=0.17$ spectrum as the center of a broad mid-frequency spectral range and $1.5 \mathrm{kHz}$ as the center of a somewhat more narrow low-frequency range for the baseline landing gear. It is believed that coherent reflections at and about $1 \mathrm{kHz}$ interfere with a clear Strouhal behavior of the spectra at this frequency.

\section{Spectral Directivity}

Figure 14 shows the baseline model polar directivity effects on spectra (using microphone 35) for flyover observer positions near an azimuthal angle $\phi_{e}$ of zero and emission polar angles of $\theta_{e}=56.0^{\circ}, 87.1^{\circ}$, and $122.1^{\circ}$, acquired at a tunnel Mach number of 0.17. The upstream spectrum is louder by about 7-8 $\mathrm{dB}$ compared to downstream, but with nearly the same spectral shape. At the polar angle nearest $90^{\circ}$, the spectral levels approach the higher upstream levels below $10 \mathrm{kHz}$, but are nearer the lower downstream levels at frequencies above that. Note that the shear layer amplitude corrections applied to the data contributed about $4 \mathrm{~dB}$ to the upstream and downstream direction amplitude difference. This is very much in-line with previously validated usage. See

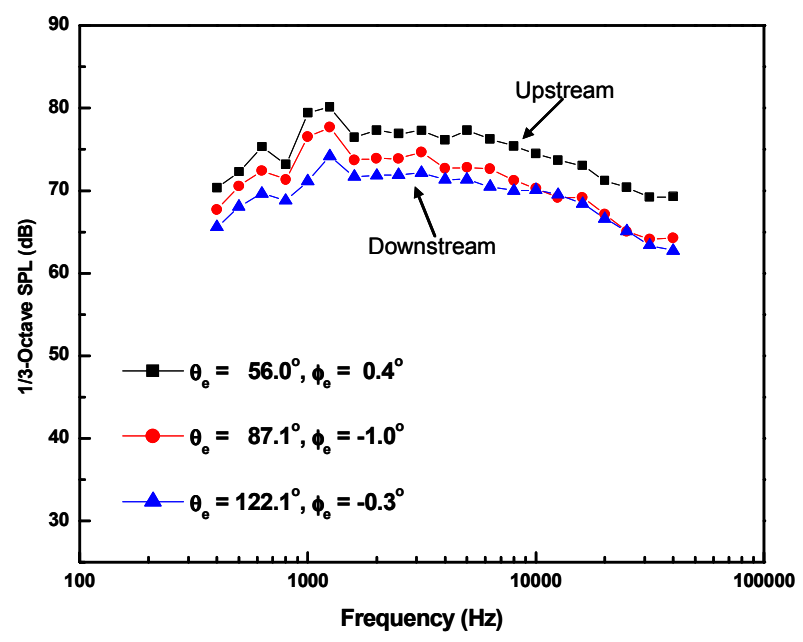

Figure 14. Polar directivity, $M=0.17$.

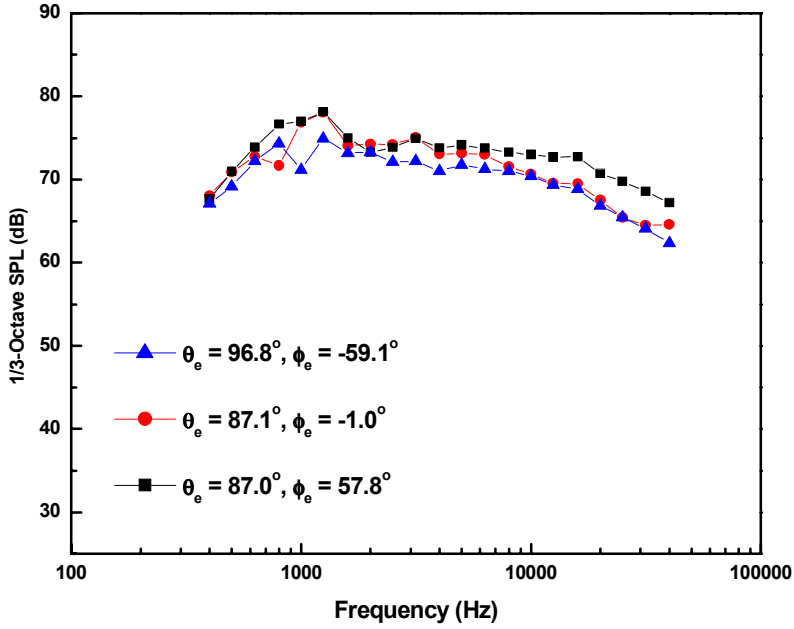

Figure 15. Azimuthal directivity, $M=0.17$.

Appendix A for a list of similar corrections for microphone 1 at the array center.

An examination of the azimuthal directivity for the same case is shown for polar angles near $90^{\circ}$ in Fig. 15 . The azimuthal angles cover a range of approximately -60 to +60 degrees. The spectra show higher overall levels for the non-door side of the baseline model compared to the door side. The flyover observer position spectrum (shown also in Fig. 14) matches the higher spectrum levels of the non-door side at lower frequencies and matches the lower levels on the door side at higher frequencies. The polar and azimuthal ranges presented in Figs. 14 and 15 correspond to important flyover and sideline ranges for ground observers for full-scale aircraft approach conditions. In the following section, detailed contour presentations give a much more complete definition of directivity

\section{Polar / Azimuthal Directivity - Baseline Gear}

For the four landing gear configurations of Fig. 1, a series of one-third octave SPL contours were created as a function of emission polar and azimuthal angle for the $\mathrm{M}=0.17$ tunnel speed condition. As previously discussed, spectra from the individual array microphones 35, 37, 39, and 41 (shown in Fig. 6), with background subtracted, were used rather than the full array to increase the number of available observation locations. The observer angle range is listed in Table I. A perspective view of the hemispherical directivity for the $10 \mathrm{kHz}$ one-third octave band for the baseline configuration is shown in Fig. 16. Note that an observer on the ground directly underneath the gear 


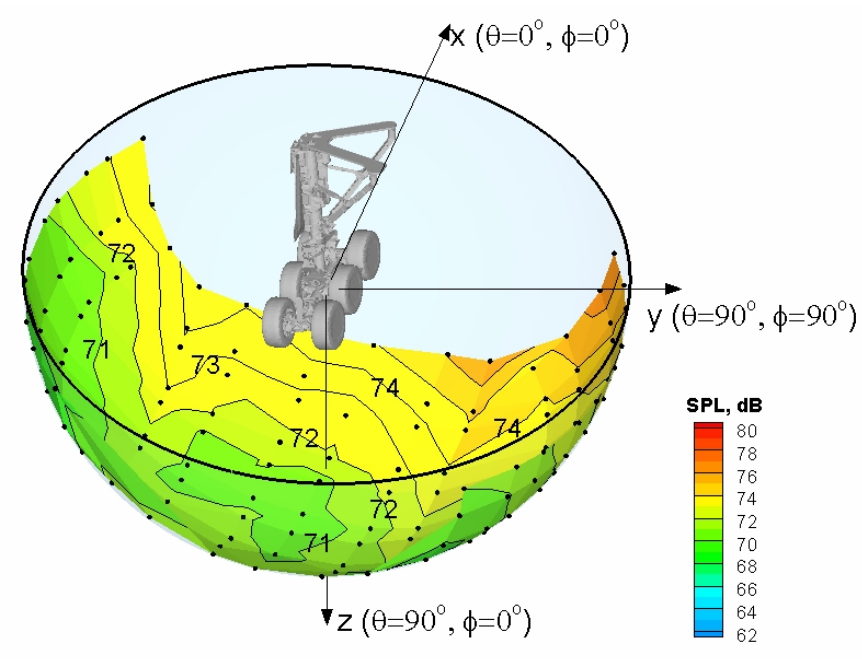

Figure 16. Hemispherical noise directivity contours, $M=0.17$.

would be located at the bottom center of the hemisphere at polar and azimuthal angles of $\theta_{e}=90^{\circ}$ and $\phi_{e}=0^{\circ}$, respectively. To aid comparison between different directivities, the three-dimensional geometry of Fig. 16 was replaced by a two-dimensional projection yielding the contour plots shown in Figs. 17 and 18. The top of each contour corresponds to a position forward of the aircraft and the right side is the aircraft starboard side. A silhouette of the model appears in each plot at a location corresponding to an observer standing directly underneath the gear. The small crosses shown represent the microphone measurement locations.

Figure 17 shows contours for the baseline model and the gear without the oleo side door for frequency bands spanning $630 \mathrm{~Hz}$ through $40 \mathrm{kHz}$. Each successive plot represents a doubling of the one-third octave frequency. The same color level scale is shown for all contours. As expected and seen in the spectra of Fig. 14, higher noise levels are found at the smaller polar angles, representing noise directed forward of the aircraft. In general, there is an approximate 5 to $6 \mathrm{~dB}$ change in SPL between the upstream and downstream polar angles. This is true across the complete azimuthal angular range for all frequencies. The levels vary less azimuthally. Levels are generally higher azimuthally near the sidelines at $\phi_{e}= \pm 30^{\circ}$ and $\pm 90^{\circ}$, and somewhat lower directly under the "flight path" near $\phi_{e}=0^{\circ}$ and at sideline angles near $\pm 60^{\circ}$. The removal of the oleo side-mounded door increased overall directivity levels noticeably (about $2 \mathrm{~dB}$ ) in the $1250 \mathrm{~Hz}$ band - related perhaps to increased vortex shedding from the oleo region with the door no longer present to act as a flow-aligning baffle. With the door in place, less noise is seen at negative $\phi_{e}$ angles for all frequencies, due to apparent oleo and strut noise shielding by the door. When the door is removed, higher levels are seen at these same azimuthal locations.

\section{E. Polar / Azimuthal Directivity - Toboggan Fairing}

Figure 18 shows directivity contours for the model configurations where the toboggan fairing was mounted on the undercarriage truck. The contour level colors are the same as that of Fig. 17. Note that the gaps shown in the 40-kHz contours in Fig. 18 correspond to those regions where the background noise was too high to be subtracted comfortably. (Increased background levels due to the additional Kevlar material used for the flyover test setup were previously mentioned.) Comparison of the toboggan results to the corresponding baseline cases of Fig. 17 show both increases and decreases in noise levels. Although the results at $630 \mathrm{~Hz}$ are almost identical with the baseline gear with and without the door mounted, the levels were increased overall by several $\mathrm{dB}$ for both the 1250 and $2500 \mathrm{~Hz}$ bands. Furthermore, the results were about the same and often decreased at frequencies of $5 \mathrm{kHz}$ and higher. The decrease in level at higher frequencies is more directly seen in Fig. 19 where the spectra are compared for the almost "directly overhead" flyover observer position of $\theta_{e}=87.1^{\circ}$ and $\phi_{e}=-1.0^{\circ}$. The level-increase at frequencies below $5 \mathrm{kHz}$ is also seen. 

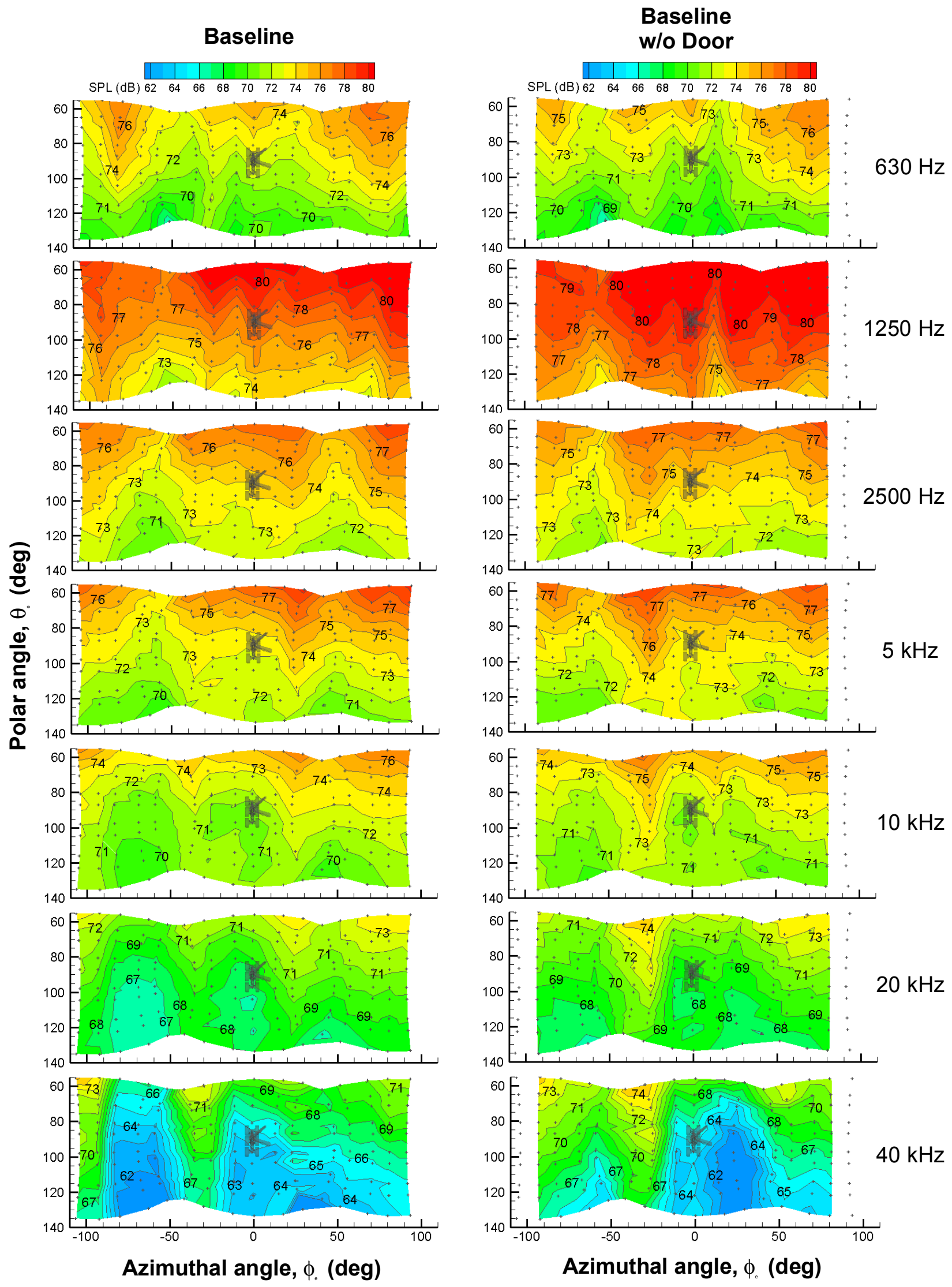

Figure 17. Polar / azimuthal noise directivity contours for baseline configurations, $\mathbf{M}=\mathbf{0 . 1 7}$. 
Toboggan

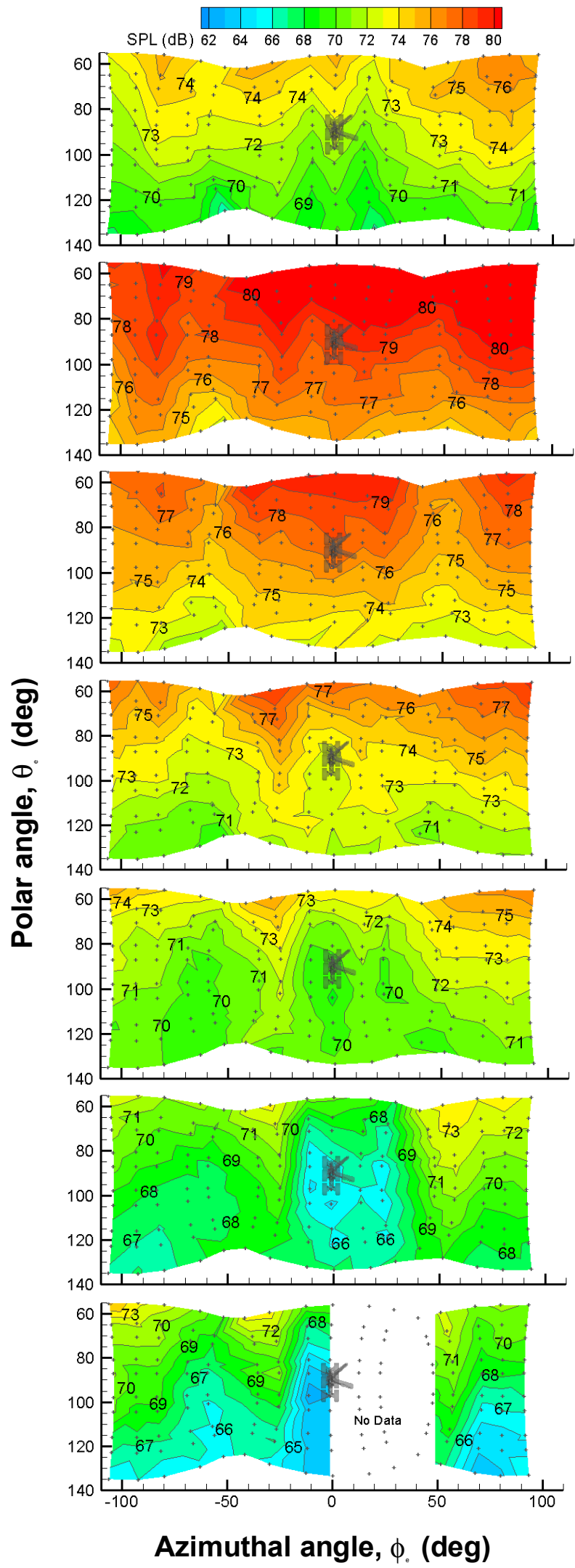

Toboggan

w/o Door
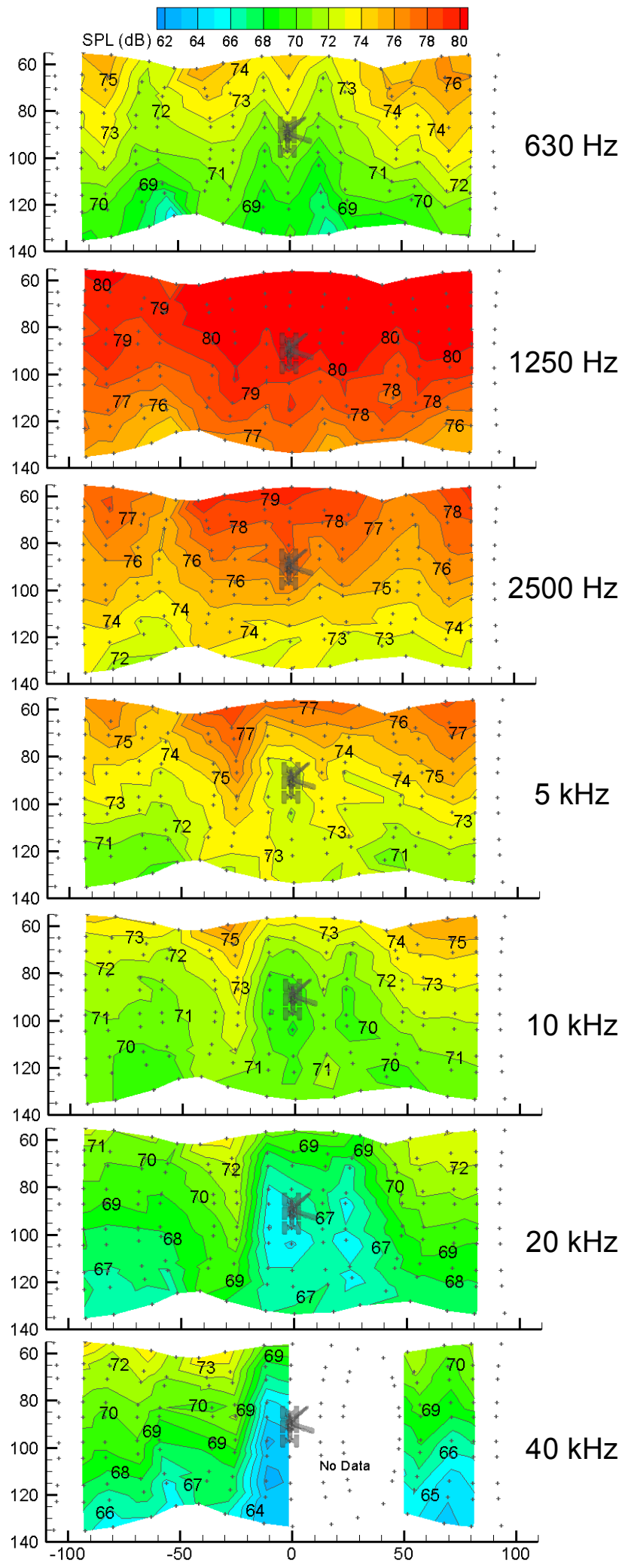

Azimuthal angle, $\phi_{0}$ (deg)

Figure 18. Polar / azimuthal noise directivity contours for toboggan configurations, $\mathbf{M}=\mathbf{0 . 1 7}$. 
Note that all of the $\mathrm{dB}$ changes induced by the toboggan fairing are relatively small, within $2 \mathrm{~dB}$. The toboggan appears to act as a bluff body noise generator at low frequencies, while it may shield higher frequency noise generated by the small-scale structures on the truck (e.g., hydraulic lines and cables). It is not known to what extent the present results could have been influenced by small-component fidelity issues as compared with an actual gear. Therefore, conclusions regarding the worth of the toboggan are necessarily limited. Nevertheless, based on the present results, it appears that the fairing may be of some value in reducing gear noise for model-scale higher frequencies (corresponding to full-scale mid frequencies).

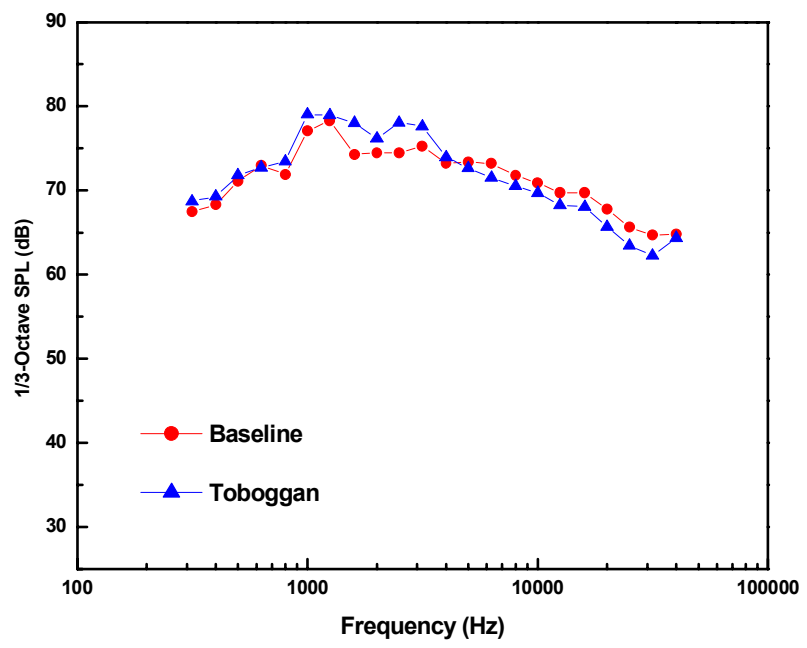

Figure 19. Flyover spectra for baseline and toboggan configurations. $M=0.17, \theta_{e}=87.1^{\circ}, \varphi_{e}=-1.0^{\circ}$

\section{Conclusion}

An extensive experimental study of landing gear noise for a scale-model test article has been conducted in the NASA Langley QFF. The study concentrated on the collection of aeroacoustic spectra and directivity data for a high-fidelity, 6.3\%-scale Boeing 777 main landing gear, with the model providing a generally faithful reproduction of flight hardware. Microphone array measurements were obtained at a number of polar and azimuthal observer angles with respect to the model and for a range of Mach numbers representing typical aircraft approach conditions. The acquired data were processed using DAMAS deconvolution to obtain global noise distribution contours. Straightforward single microphone autospectrum analysis was used to obtain spectra. Analysis of the data confirmed the expected sixth-power Mach number farfield intensity scaling law for the baseline gear. Polar and azimuthal directivity spectra and contour plots showing measured sound pressure levels as a function of polar and azimuthal angle revealed distinct directivity patterns, with higher levels of noise generally directed forward of the aircraft and away from the door side of the gear. Finally, a simple toboggan noise reduction treatment attached to the truck and designed to provide flyover shielding of the smaller components of the model showed a slight improvement in radiated noise at model-scale higher frequencies, but at the expense of slightly increased lowerfrequency noise.

\section{Appendix A - Coordinate Systems and Shear Layer Correction}

Figure A1 shows the test section coordinate system $x^{\text {tun }}, y^{\text {tun }}, z^{\text {tun }}$ referenced to the nozzle center. A landing gear model is shown mounted on a sideplate mated to the nozzle side. This corresponds to the photo of the sideline noise measurement setup of Fig. 2. The axis $x^{\text {tun }}$ is directed downstream (up) from the nozzle and $y^{\text {tun }}$ and $z^{\text {tun }}$ are aligned as shown over the face of the nozzle opening. The reference center of the gear wheel truck is located at 
$\left(x_{\mathrm{lg}}^{\text {tun }}, \mathrm{y}_{\mathrm{lg}}^{\text {tun }}, \mathrm{z}_{\mathrm{lg}}^{\text {tun }}\right)$. This corresponds to the center of the gear $\mathrm{x}^{\prime}, \mathrm{y}^{\prime}, \mathrm{z}^{\prime}$ coordinate system, which defines the position of an observer (a microphone location on the MADA or any place in the QFF) with respect to the model. The following relationship holds for this "sideline" mounting of Fig. A1.

$$
\begin{aligned}
& x^{\prime}=-\left(x^{\text {tun }}-x_{l g}^{\text {tun }}\right) \\
& y^{\prime}=z^{\text {tun }}-z_{l g}^{\text {tun }} \\
& z^{\prime}=y^{\text {tun }}-y_{l g}^{\text {tun }}
\end{aligned}
$$

For the model mounted on the sideline sideplate,

$$
\mathrm{x}_{\mathrm{lg}}^{\mathrm{tun}}=35^{\prime \prime}, \mathrm{y}_{\mathrm{lg}}^{\mathrm{tun}}=-8^{\prime \prime} \text {, and } \mathrm{z}_{\mathrm{lg}}^{\mathrm{tun}}=-.5^{\prime \prime}
$$

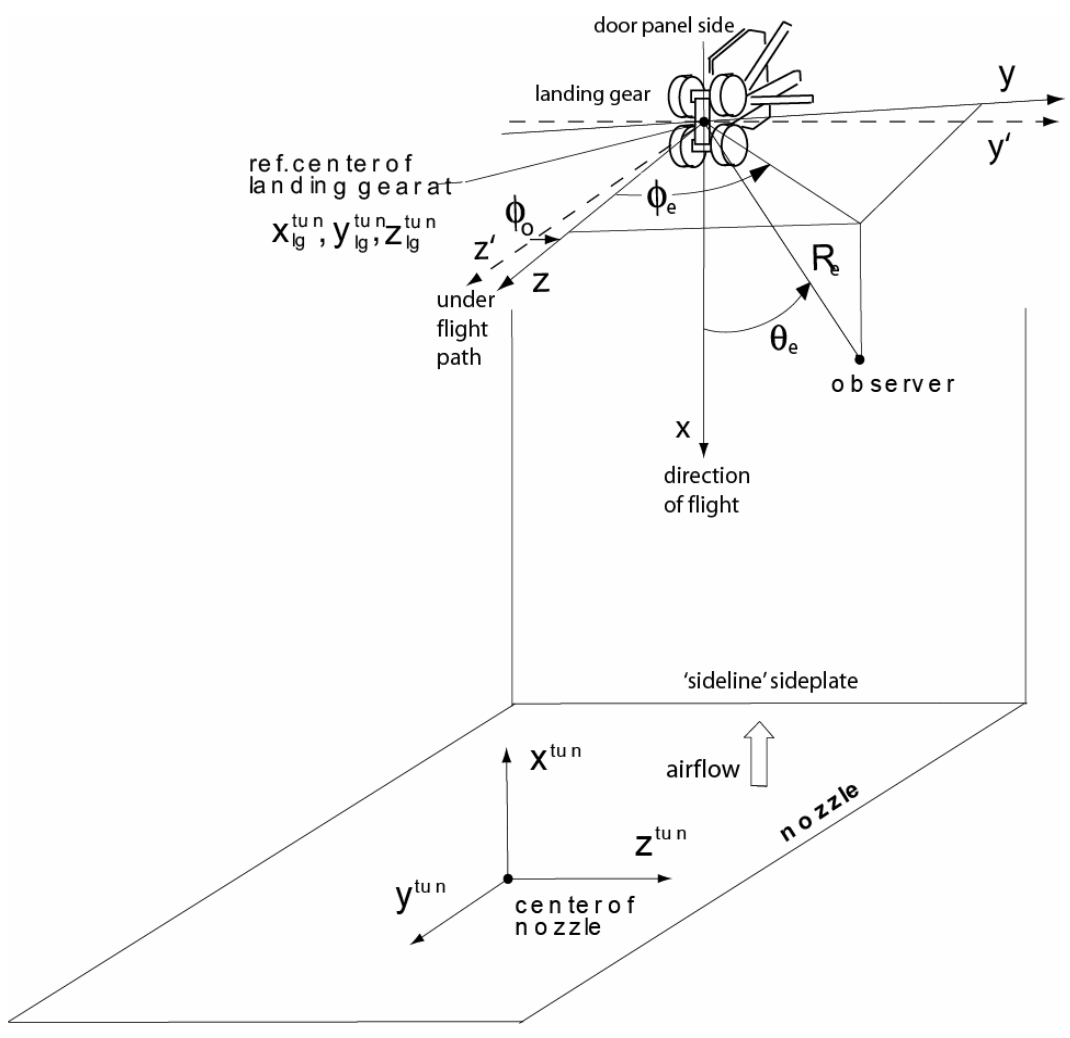

Figure A1. QFF landing gear polar coordinates with respect to the QFF nozzle coordinate system.

The model is mounted such that the strut and wheel truck assembly is at a six-degree offset from the sideplate mount. (The model's base was built to be tilted six degrees to mate with a B777 fuselage model.) For consistency with traditional airframe directivity definitions, the coordinates attached to the model are thus rotated by $\phi_{0}=6^{\circ}$ in the $\mathrm{y}, \mathrm{z}$ plane. The rotated coordinates $\mathrm{x}, \mathrm{y}, \mathrm{z}$ are related to $\mathrm{x}^{\prime}, \mathrm{y}^{\prime}, \mathrm{z}^{\prime}$ by 


$$
\begin{aligned}
& \mathrm{x}=\mathrm{x}^{\prime} \\
& \mathrm{y}=\mathrm{y}^{\prime} \operatorname{Cos} \phi_{0}-\mathrm{z}^{\prime} \operatorname{Sin} \phi_{0} \\
& \mathrm{z}=\mathrm{z}^{\prime} \operatorname{Cos} \phi_{0}+\mathrm{y}^{\prime} \operatorname{Sin} \phi_{0}
\end{aligned}
$$

with $\mathrm{x}, \mathrm{y}, \mathrm{z}$ centered on the wheel truck, and $\mathrm{y}$ aligned with the wheel axes. The illustrated spherical coordinate system in Fig. A1 locates an observer at a distance $\mathrm{R}_{\mathrm{e}}$, polar angle $\theta_{e}$, and azimuth angle $\phi_{e}$.

In Fig. A2, the plan view of the landing gear sideline test setup, including the out-of-flow MADA array at several measurement positions, is shown. The MADA is mounted on a boom, with microphones directed toward and 60 inches away from the boom's rotational center. The boom is rotated about a line which is parallel to the $\mathrm{y}^{\text {tun }}$ axis and centered about $x^{\text {tun }}=39.5^{\prime \prime}$ and $\mathrm{z}^{\text {tun }}=0.5^{\prime \prime}$. All positions shown in Fig. A2 are for the array boom elevations of $\Phi_{\text {MADA }}$ at $+/-90^{\circ}$ where the array and boom are horizontal and thus level with the boom rotational center. To define array positions, positive $\mathrm{z}^{\text {tun }}$ is taken to be on the negative MADA elevation angle $\Phi_{\text {MADA }}$ side and negative $\mathrm{z}^{\text {tun }}$ is taken as being on the positive $\Phi_{\text {MADA }}$ side. $\Phi_{\text {MADA }}=0^{0}$ is directed downstream in the positive $\mathrm{x}^{\text {tun }}$ direction. The MADA boom azimuth angle is defined by $\Psi_{\text {MADA }}$, with $\Psi_{\text {MADA }}=0^{0}$ being in line with the $\mathrm{z}^{\text {tun }}$ axis. Positive $\Psi_{\text {MADA }}$ is measured from the $z^{\text {tun }}$ axis toward the $\mathrm{y}^{\text {tun }}$ axis on the $\mathrm{y}^{\text {tun }}, \mathrm{z}^{\text {tun }}$ plane.

In Fig. A3, a plan view of the landing gear flyover mounting is shown. For this test configuration, a flyover sideplate is added in the QFF setup and nothing is mounted to the sideline sideplate. (Note that in Fig. A3, compared to Fig. A2, the orientation of the sign of $\Psi_{\text {MADA }}$ is reversed. In Fig. 3, positive $\Psi_{\text {MADA }}$ is in the direction of the negative- $\mathrm{y}^{\text {tun }}$ axis from the $z^{\text {tun }}$ axis, as per the manner the data was logged during testing.) For the gear flyover mounting, the following relationship holds for an observer regarding the (non-rotated) model $\mathrm{X}^{\prime}, \mathrm{y}^{\prime}, \mathrm{z}^{\prime}$ coordinates as compared with the same QFF $\mathrm{x}^{\text {tun }}, \mathrm{y}^{\text {tun }}, \mathrm{z}^{\text {tun }}$ coordinates,
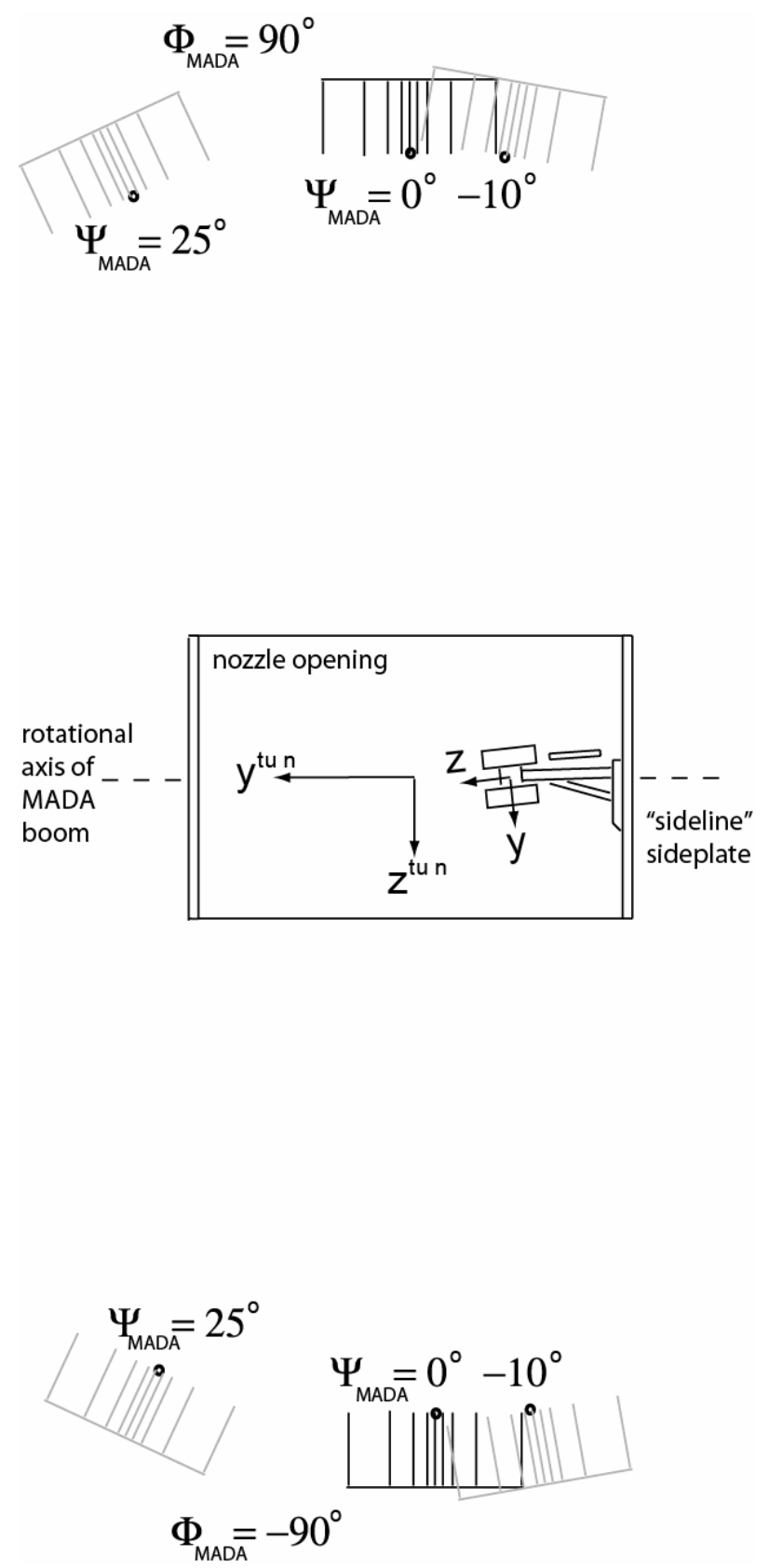

Figure A2. Sketch of QFF landing gear sideline array measurement by MADA (approximate scale). 


$$
\begin{aligned}
& z^{\prime}=z^{\text {tun }}-z_{\mathrm{lg}}^{\text {tun }} \\
& y^{\prime}=-\left(y^{\text {tun }}-y_{\mathrm{lg}}^{\text {tun }}\right) \\
& x^{\prime}=-\left(x^{\text {tun }}-x_{\lg }^{\text {tun }}\right)
\end{aligned}
$$

For the model mounted on the flyover sideplate

$\mathrm{x}_{\mathrm{lg}}^{\mathrm{tun}}=33.75^{\prime \prime}, \mathrm{y}_{\mathrm{lg}}^{\mathrm{tun}}=0^{\prime \prime}, \mathrm{z}_{\mathrm{lg}}^{\mathrm{tun}}=-2.0^{\prime \prime}$

Here, as with the sideline mounting shown in Fig. A2, the relationship Eq. (A3) remains valid between the rotated coordinates $\mathrm{x}, \mathrm{y}, \mathrm{z}$ and $\mathrm{x}^{\prime}, \mathrm{y}^{\prime}, \mathrm{z}^{\prime}$.

For the spherical coordinated system attached to the model, the following relationships hold. The polar angle $\theta$ is measured from the forward $\mathrm{X}$ direction,

$$
\begin{aligned}
\theta=\tan ^{-1}\left(\sqrt{\mathrm{y}^{2}+\mathrm{z}^{2}} / \mathrm{x}\right)= \\
\quad \cos ^{-1}\left(\mathrm{x} / \sqrt{\mathrm{x}^{2}+\mathrm{y}^{2}+\mathrm{z}^{2}}\right)
\end{aligned}
$$

and the azimuthal angle $\phi$ is referenced from the flyover $\mathrm{Z}$ axis, with positive directed toward the $\mathrm{y}$ axis (starboard side of aircraft),

$$
\phi=\tan ^{-1}(\mathrm{y} / \mathrm{z})
$$

The observer distance is

$$
\mathrm{R}=\sqrt{\mathrm{x}^{2}+\mathrm{y}^{2}+\mathrm{z}^{2}}
$$
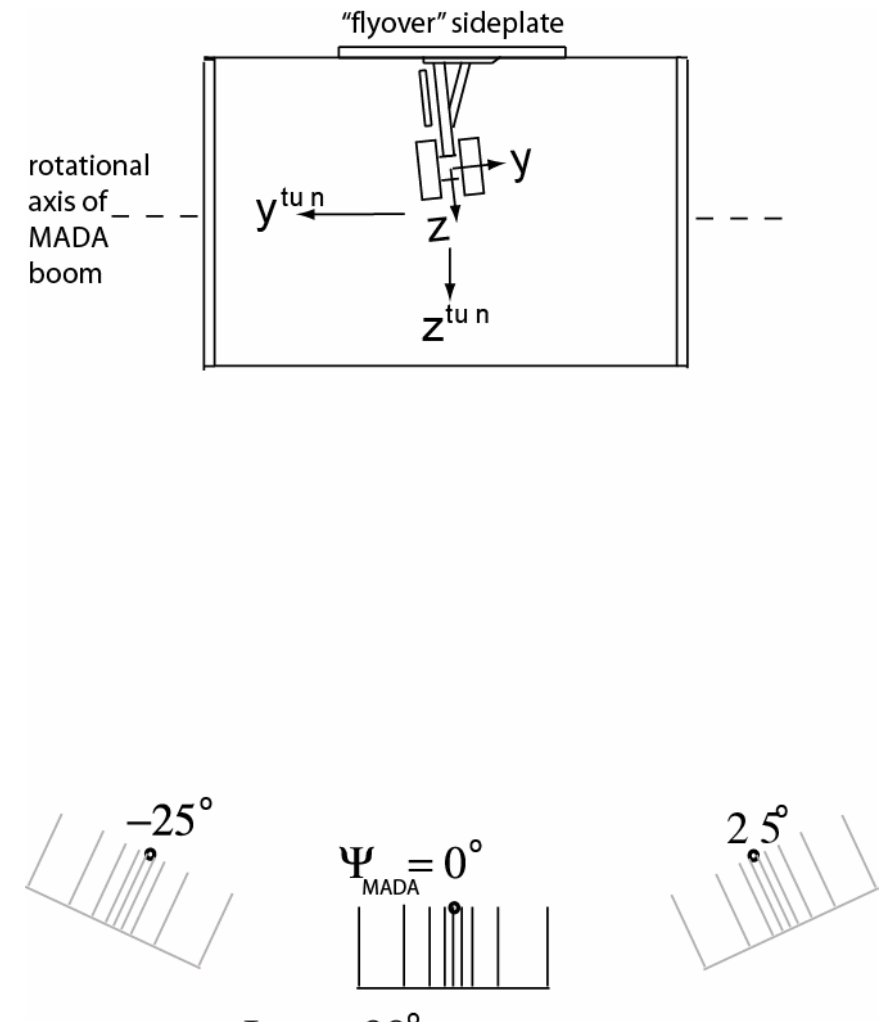

$\Phi_{\text {MADA }}=-90^{\circ}$ Figure A3. Sketch of QFF landing gear flyover array
measurement by MADA (approximate scale).

Table A1 gives key array / model geometry and shear layer refraction corrections for the test cases of this study for a tunnel Mach number of 0.17. These values are for microphone 1 at the center of the MADA. They are thus representative of the mean array values. In the use of the array microphones for beamform processing and the use of individual microphone spectra, each microphone is separately accounted for, and will have values different from that listed. For each boom elevation angle $\Phi_{\text {MADA }}$ and each MADA azimuth angle $\Psi_{\text {MADA }}$ on the boom, the table lists the tunnel (mechanical) polar angle $\theta$ of Eq. (A6) and the tunnel (mechanical) azimuthal angle $\phi$ of Eq. (A7) for microphone 1 with respect to the landing gear model reference point at the $\mathrm{x}, \mathrm{y}, \mathrm{z}$ origin. Corresponding to these are the emission polar angle $\theta_{e}$ and the emission azimuthal sideline angle $\phi_{e}$ shown in Fig. 4 as the primary coordinate system used in this report for directivity definition. Figure 7 illustrates the relationship between the mechanical and emission polar angles, $\theta$ and $\theta_{e}$, respectively. Note that the $\phi$ and $\phi_{e}$ values are equal because of the acoustic ray path and shear layer orientations with respect to the coordinate system. The emission distance $R_{e}$ and the mechanical distance $R_{m}$ are equated in the emission coordinate determination procedure. This value is used to adjust amplitudes to correspond to those at $R=60$ inches. These values are listed in Table A1. The Amiet ${ }^{30}$ thin shear layer refraction amplitude correction, as well as the total correction level, is listed. 


\begin{tabular}{|c|c|c|c|c|c|c|c|c|c|}
\hline$\Phi$ & $\Psi$ & $\theta$ & $\phi$ & $\theta_{e}$ & $\phi_{e}$ & $\begin{array}{c}R_{\mathrm{m}}= \\
\mathbf{R}_{\mathrm{e}}\end{array}$ & $\begin{array}{c}R_{e}= \\
60^{\prime \prime}\end{array}$ & $\begin{array}{l}\text { Shear } \\
\text { Layer } \\
\text { Amp. } \\
\text { Correct }\end{array}$ & $\begin{array}{c}\text { Overall } \\
\text { Single } \\
\text { Mic Amp. } \\
\text { Correct }\end{array}$ \\
\hline deg & deg & deg & deg & deg & deg & inches & dB & dB & dB \\
\hline-124 & $\mathbf{0}$ & 60.5 & 75.0 & 60.7 & 75.0 & $\mathbf{5 9 . 0}$ & 0.14 & 1.82 & 1.96 \\
\hline-107 & $\mathbf{0}$ & 77.5 & 76.2 & 76.0 & 76.2 & 60.4 & -0.05 & 0.85 & 0.80 \\
\hline-90 & $\mathbf{0}$ & 94.2 & 76.5 & 92.2 & 76.5 & 61.7 & -0.24 & -0.13 & -0.37 \\
\hline-73 & $\mathbf{0}$ & 110.5 & 76.2 & 109.4 & 76.2 & 62.9 & -0.41 & -1.09 & -1.50 \\
\hline-56 & $\mathbf{0}$ & 126.5 & 75.0 & 127.5 & 75.0 & 63.9 & -0.55 & -1.95 & -2.50 \\
\hline 56 & $\mathbf{0}$ & 127.6 & -86.7 & 129.0 & -86.7 & 62.4 & -0.33 & -2.03 & -2.36 \\
\hline 73 & $\mathbf{0}$ & 111.2 & -87.9 & 110.2 & -87.9 & 61.1 & -0.15 & -1.14 & -1.29 \\
\hline 90 & $\mathbf{0}$ & 94.3 & -88.3 & 92.4 & -88.3 & 59.7 & 0.04 & -0.15 & -0.11 \\
\hline 107 & $\mathbf{0}$ & 77.1 & -87.9 & 75.7 & -87.9 & 58.4 & 0.23 & 0.87 & 1.10 \\
\hline 124 & $\mathbf{0}$ & 59.5 & -86.7 & 60.0 & -86.7 & 57.3 & 0.40 & 1.88 & 2.28 \\
\hline-124 & -10 & 60.3 & 86.8 & 60.5 & 86.8 & 57.6 & 0.35 & 1.83 & 2.18 \\
\hline-107 & -10 & 77.5 & 86.4 & 75.9 & 86.4 & $\mathbf{5 9 . 0}$ & 0.15 & 0.85 & 1.00 \\
\hline-90 & -10 & 94.3 & 86.3 & 92.3 & 86.3 & 60.3 & -0.04 & -0.14 & -0.18 \\
\hline-73 & -10 & 110.7 & 86.4 & 109.6 & 86.4 & 61.5 & -0.22 & -1.10 & -1.32 \\
\hline-56 & -10 & 126.9 & 86.8 & 127.9 & 86.8 & 62.6 & -0.36 & -1.96 & -2.32 \\
\hline 56 & -10 & 128.0 & -98.9 & 129.4 & -98.9 & 61.0 & -0.14 & -2.04 & -2.18 \\
\hline 73 & -10 & 111.4 & -98.5 & 110.5 & -98.5 & 59.7 & 0.05 & -1.15 & -1.10 \\
\hline 90 & -10 & 94.4 & -98.4 & 92.5 & -98.4 & 58.3 & 0.25 & -0.15 & 0.10 \\
\hline 107 & -10 & 77.1 & -98.5 & 75.6 & -98.5 & $\mathbf{5 7 . 0}$ & 0.44 & 0.87 & 1.31 \\
\hline 124 & -10 & 59.3 & -98.9 & 59.8 & -98.9 & 55.9 & 0.62 & 1.89 & 2.51 \\
\hline-124 & 25 & 65.5 & 48.1 & 64.7 & 48.1 & 62.5 & -0.36 & 1.53 & 1.17 \\
\hline-107 & 25 & 79.7 & 51.8 & 77.8 & 51.8 & 63.7 & -0.51 & 0.73 & 0.22 \\
\hline-90 & 25 & 94.0 & 52.9 & 91.8 & 52.9 & 64.8 & -0.67 & -0.11 & -0.78 \\
\hline-73 & 25 & 108.0 & 51.8 & 106.4 & 51.8 & 65.9 & -0.81 & -0.93 & -1.74 \\
\hline-56 & 25 & 121.5 & 48.1 & 121.2 & 48.1 & 66.8 & -0.93 & -1.63 & -2.56 \\
\hline 56 & 25 & 122.3 & -58.9 & 122.2 & -58.9 & 65.4 & -0.75 & -1.69 & -2.44 \\
\hline 73 & 25 & 108.5 & -62.8 & 107.1 & -62.8 & 64.3 & -0.60 & -0.96 & -1.56 \\
\hline 90 & 25 & 94.1 & -64.0 & 92.0 & -64.0 & 63.1 & -0.44 & -0.12 & -0.56 \\
\hline 107 & 25 & 79.4 & -62.8 & 77.6 & -62.8 & 62.0 & -0.28 & 0.74 & 0.46 \\
\hline 124 & 25 & 64.9 & -58.9 & 64.3 & -58.9 & 61.1 & -0.15 & 1.57 & 1.42 \\
\hline-124 & 0 & 62.0 & -6.0 & 61.7 & -6.0 & 59.2 & 0.12 & 1.73 & 1.85 \\
\hline-107 & 0 & 78.9 & -6.0 & 77.0 & -6.0 & 61.0 & -0.15 & 0.77 & 0.62 \\
\hline-90 & 0 & 95.3 & -6.0 & 93.1 & -6.0 & 62.8 & -0.39 & -0.19 & -0.58 \\
\hline-73 & $\mathbf{0}$ & 111.3 & -6.0 & 110.0 & -6.0 & 64.3 & -0.59 & -1.11 & -1.70 \\
\hline-56 & 0 & 127.0 & -6.0 & 127.7 & -6.0 & 65.4 & -0.74 & -1.92 & -2.66 \\
\hline-124 & -25 & 65.4 & 22.1 & 64.4 & 22.1 & 59.3 & 0.10 & 1.53 & 1.63 \\
\hline-107 & -25 & 80.4 & 19.0 & 78.3 & 19.0 & 61.0 & -0.14 & 0.69 & 0.55 \\
\hline-90 & -25 & 95.3 & 18.0 & 92.9 & 18.0 & 62.5 & -0.36 & -0.17 & -0.53 \\
\hline-73 & -25 & 109.8 & 19.0 & 108.1 & 19.0 & 63.9 & -0.55 & -1.01 & -1.56 \\
\hline-56 & -25 & 123.8 & 22.1 & 123.7 & 22.1 & 64.9 & -0.68 & -1.72 & -2.40 \\
\hline-124 & 25 & 65.4 & -34.1 & 64.4 & -34.1 & 59.3 & 0.10 & 1.53 & 1.63 \\
\hline-107 & 25 & 80.4 & -31.0 & 78.3 & -31.0 & 61.0 & -0.14 & 0.69 & 0.55 \\
\hline-90 & 25 & 95.3 & -30.0 & 92.9 & -30.0 & 62.5 & -0.36 & -0.17 & -0.53 \\
\hline-73 & 25 & 109.8 & -31.0 & 108.1 & -31.0 & 63.9 & -0.55 & -1.01 & -1.56 \\
\hline-56 & 25 & 123.8 & -34.1 & 123.7 & -34.1 & 64.9 & -0.68 & -1.72 & -2.40 \\
\hline
\end{tabular}

Table A1. QFF and LG Coordinates and Shear Layer Corrections for Array Center, $M=0.17$. 


\section{Acknowledgments}

The authors wish to thank Ronald Geouge and Jaye Moen of NASA Langley, Dennis Kuchta of Jacobs Sverdrup Inc., and Lawrence Becker and Daniel Stead of Lockheed Martin for their invaluable assistance with data acquisition, data reduction, software development, and general support for this study. The authors also thank Dr. Mehdi Khorrami of NASA Langley for his assistance with the design and fabrication of the toboggan noise treatment and Drs. William Devenport and Patricio Ravetta of the Virginia Polytechnic Institute and State University for their assistance with the selection and installation of the Kevlar ${ }^{\mathrm{B}}$ fabric in the QFF.

\section{References}

${ }^{1}$ Brooks, T. F., and Humphreys, W. M., Jr., "Flap-edge Aeroacoustic Measurements and Predictions," Journal of Sound and Vibration, vol. 261, pp. 31-74, 2003.

${ }^{2}$ Mendoza, J. M., Brooks, T. F., and Humphreys, W. M., Jr., "An Aeroacoustic Study of a Leading Edge Slat Configuration," International Journal of Aeroacoustics, vol. 1, pp. 241-274, 2002.

${ }^{3}$ Heller, H., and Dobrzynski, W., "Sound Radiation from Aircraft Wheel-Well / Landing-Gear Configurations," Journal of Aircraft, vol. 14, no. 8, pp. 768 - 774, 1977.

${ }^{4}$ Fink, M. R., "Airframe Noise Prediction Method," FAA Report FAA-RD-77-29, 1979.

${ }^{5}$ Fink, M. R., "Noise Component Method for Airframe Noise," Journal of Aircraft, vol. 16, pp. 659-665, 1979.

${ }^{6}$ Dobrzynski, W., and Buchholz, H., "Full-Scale Noise Testing on Airbus Landing Gears in the German Dutch Wind Tunnel," AIAA Paper 97-1597, $3^{\text {rd }}$ AIAA/CEAS Aeroacoustics Conference, Atlanta, GA, 1997.

${ }^{7}$ Dobrzynski, W., Chow, L.C., Guion, P., and Shiells, D., "A European Study on Landing Gear Airframe Noise Sources," AIAA Paper 2000-1971, $6^{\text {th }}$ AIAA/CEAS Aeroacoustics Conference, Lahaina, HI, 2000.

${ }^{8}$ Michel, U., and Qiao, W., "Directivity of Landing-Gear Noise Based on Flyover Measurements," AIAA Paper 99-1956, $5^{\text {th }}$ AIAA/CEAS Aeroacoustics Conference, Bellevue, WA, 1999.

${ }^{9}$ Jaeger, S., Burnside, N., Soderman, P., Horne, W.C., and James, K., "Aeroacoustic Study of an Isolated, HighFidelity, 26\%-Scale Landing Gear Model," NASA Technical Paper 2004-212815, November, 2004.

${ }^{10}$ Horne, W.C., Burnside, N., Soderman, P., Jaeger, S., Reinero, B., James, K., and Arledge, T., "Aeroacoustic Study of a 26\%-Scale Semispan Model of a Boeing 777 Wing in the NASA Ames 40- by 80-Foot Wind Tunnel," NASA Technical Paper 2004-212802, October, 2004.

${ }^{11}$ Smith, M., and Chow, L., "Validation of a Prediction Model for Aerodynamic Noise from Aircraft Landing Gear," AIAA Paper 2002-2581, $8^{\text {th }}$ AIAA/CEAS Aeroacoustics Conference, Breckenridge, CO, 2002.

${ }^{12}$ Guo, Y., "A Statistical Model for Landing Gear Noise Prediction," Journal of Sound and Vibration, vol. 282, pp. 61-87, 2004.

${ }^{13}$ Guo, Y., "Empirical Prediction of Aircraft Landing Gear Noise," NASA Contractor Report 2005-213780, July, 2005.

${ }^{14}$ Guo, Y., "An Improved Landing Gear Noise Prediction Scheme," NASA Contractor Report for Contract NAS1-NNL04AA11B, Task NNL06AB63T, 2006.

${ }^{15}$ Hedges, L., Travin, A., and Spalart, P., "Detached-Eddy Simulations Over a Simplified Landing Gear," Journal of Fluids Engineering, vol. 124, no. 2, pp. 413-423, 2002.

${ }^{16}$ Lockard, D., Khorrami, M., "Aeroacoustic Analysis of a Simplified Landing Gear," AIAA Paper 2004-2887, $10^{\text {th }}$ AIAA/CEAS Aeroacoustics Conference, Manchester, U.K., 2004.

${ }^{17}$ Herkes, W., Olsen, R., and Uellenberg, S., "The Quiet Technology Demonstrator Program: Flight Validation of Airplane Noise-Reduction Concepts," AIAA Paper 2006-2720, $12^{\text {th }}$ AIAA/CEAS Aeroacoustics Conference, Boston, MA, 2006.

${ }^{18}$ Pott-Pollenske, M., Dobrzynski, W., Buchholz, H., Guerin, S., Saueressig, G, and Finke, U., "Airframe Noise Characteristics from Flyover Measurements and Predictions," AIAA Paper 2006-2567, $12^{\text {th }}$ AIAA/CEAS Aeroacoustics Conference, Boston, MA, 2006.

${ }^{19}$ Ravetta, P., Burdisso, R., and Ng, W., "Wind Tunnel Aeroacoustic Measurements of a 26\%-scale 777 Main Landing Gear," AIAA Paper 2004-2885, $10^{\text {th }}$ AIAA/CEAS Aeroacoustics Conference, Manchester, U.K., 2004.

${ }^{20}$ Humphreys, W. M., Jr., Shams, Q. A., Graves, S. S., Sealey, B. S., Bartram, S. M., and Comeaux, T., "Application of MEMS Microphone Array Technology to Airframe Noise Measurements," AIAA Paper 2005-3004, $11^{\text {th }}$ AIAA/CEAS Aeroacoustics Conference, Monterey, CA, 2005. 
${ }^{21}$ Burley, C. L., Brooks, T. F., Humphreys, W. M., Jr., and Rawls, J. W., Jr., “ANOPP Landing Gear Noise Prediction Comparisons to Model-Scale Data," AIAA Paper 2007-3459, $13^{\text {th }}$ AIAA/CEAS Aeroacoustics Conference, Rome, Italy, 2007.

${ }^{22}$ Elkoby, R., Brusniak, L., Stoker, R., Khorrami, M., Abeysinge, A., and Moe, J., "Airframe Noise Reduction from the QTD II Flight Test Program," AIAA Paper 2007-3457, 13 ${ }^{\text {th }}$ AIAA/CEAS Aeroacoustics Conference, Rome, Italy, 2007.

${ }^{23}$ Stoker, R. W., and Sen, R., "An Experimental Investigation of Airframe Noise Using a Model-Scale Boeing 777," AIAA Paper 2001-0987, 39 $9^{\text {th }}$ AIAA Aerospace Sciences Meeting and Exhibit, Reno, NV, 2001.

${ }^{24}$ Hubbard, H., "Aeroacoustic Research Facilities at NASA Langley Research Center," NASA Technical Memorandum 84585, 1983.

${ }^{25}$ Humphreys, W. M., Jr., Brooks, T. F., Hunter, W. W., Jr., and Meadows, K. R., "Design and Use of Microphone Directional Arrays for Aeroacoustic Measurements," AIAA Paper 1998-0471, 36 ${ }^{\text {th }}$ AIAA Aerospace Sciences Meeting and Exhibit, Reno, NV, 1998.

${ }^{26}$ Brooks, T. F., and Humphreys, W. M., Jr., "A Deconvolution Approach for the Mapping of Acoustic Sources (DAMAS) Determined from Phased Microphone Arrays," Journal of Sound and Vibration, vol. 294, pp. 856-879, 2006.

${ }^{27}$ Brooks, T. F., and Humphreys, W. M., Jr., "Some Three-Dimensional Applications of DAMAS Methodology for Aeroacoustic Noise Source Definition," AIAA Paper 2005-2960, $11^{\text {th }}$ AIAA/CEAS Aeroacoustics Conference, Monterey, CA, 2005.

${ }^{28}$ Brooks, T. F., and Humphreys, W. M., Jr., "Extension of DAMAS Phased Array Processing for Spatial Coherence Determination (DAMAS-C)," AIAA Paper 2006-2654, $12^{\text {th }}$ AIAA/CEAS Aeroacoustics Conference, Cambridge, MA, 2006.

${ }^{29}$ Brooks, T. F., Marcolini, M. A., and Pope, D. S., "A Directional Array Approach for the Measurement of Rotor Noise Source Distributions with Controlled Spatial Resolution," Journal of Sound and Vibration, vol. 112, no. 1, pp. 192-197, 1987.

${ }^{30}$ Amiet, R. K., "Refraction of Sound by a Shear Layer," Journal of Sound and Vibration, vol. 58, no. 3, pp. 467482,1978 .

${ }^{31}$ Jaeger, S. M., Horne, W. C., and Allen, C. S., "Effect of Surface Treatment on Array Microphone Self-Noise," AIAA Paper 2000-1937, $21^{\text {st }}$ AIAA/CEAS Aeroacoustics Conference, Lahaina, HI, 2000. 